UNIVERSIDADE DE BRASÍLIA

FACULDADE DE EDUCAÇÃO FÍSICA

PROGRAMA DE PÓS-GRADUAÇÃO STRICTO-SENSU EM EDUCAÇÃO FÍSICA

\title{
DISTRIBUIÇÃO DE PRESSÃO PLANTAR DURANTE O CORRER EM CRIANÇAS
}

Tainá Neves Vieira

BRASÍLIA

2014 


\title{
DISTRIBUIÇÃO DE PRESSÃO PLANTAR DURANTE O CORRER EM CRIANÇAS
}

\section{Tainá Neves Vieira}

\begin{abstract}
Dissertação apresentada à Faculdade de Educação Física da Universidade de Brasília, como requisito parcial para obtenção do grau de Mestre em Educação Física.
\end{abstract}

ORIENTADOR: PROF ${ }^{\mathrm{a}}$. DR ${ }^{\mathrm{a}}$. ANA CRISTINA DE DAVID 


\title{
DISTRIBUIÇÃO DE PRESSÃO PLANTAR DURANTE \\ O CORRER EM CRIANÇAS
}

\begin{abstract}
Dissertação aprovada como requisito parcial para obtenção do título de Mestre em Educação Física pelo Programa de Pós Graduação da Faculdade de Educação Física da Universidade de Brasília.
\end{abstract}

Banca Examinadora:

Prof $^{\mathrm{a}}$. Dr ${ }^{\mathrm{a}}$. Ana Cristina de David

(Orientadora - FEF/UnB)

Prof. Dr. Tiago Guedes Russomano

(Examinador Interno - FEF/UnB)

Prof. Dr. Levy Aniceto Santana

(Examinador Externo - Universidade Católica de Brasília)

Prof. Dr. Rinaldo André Mezzarane

(Examinador Suplente - FEF/UnB)

Brasília - DF, 08 de dezembro de 2014. 


\section{DEDICATÓRIA}

Aos meus avós e mãe que se empenharam tanto na minha educação e ao Erik sempre companheiro e compreensivo, dedico. 


\section{AGRADECIMENTOS}

Agradeço a minha família por ter me apoiado tanto durante as minhas escolhas. Em especial aos meus avós Gercina e João, que desde os meus primeiros anos de vida garantiram, acima de tudo, que eu recebesse um boa educação e foram exemplos que fizeram com que eu sonhasse longe, e a minha mãe, que nunca mediu esforços para ser a melhor mãe, que nos formou críticos e determinados (e que imprimiu artigos, fez revisão ortográfica, lanchinhos e almoços quando eu não estava muito preocupada com isso). Serei sempre grata a vocês pelo exemplo de vida que são!

Aos meus irmãos, que serão sempre companheiros, não importa qual seja a próxima tarefa. A pequena Luísa, por trazer tanta alegria a minha vida. Aos meus primos e tias agradeço por compreenderem a minha constante ausência nos eventos familiares.

A Ana Cristina de David, minha orientadora, por oferecer e ensinar tanto. Agradeço pela oportunidade de evoluir profissionalmente ao seu lado, pela compreensão, incentivo e estímulo oferecidos durante todo o mestrado. Aprendi e cresci muito durante o mestrado, profissionalmente e pessoalmente, e sou muito grata a você por isso.

Agradeço também a todos os colegas de mestrado, que de várias formas fizeram parte do processo da minha formação: Bruna, Guigo, Andréia, Leandra. Agradeço a Paula, Raphael, Letícia, Elias pela ajuda valiosa durante a coleta de dados e o apoio durante o período que estive na Alemanha.

Agradeço aos professores que, de alguma forma, contribuíram para a minha formação e para a construção desse trabalho. Agradeço com muito carinho a Rossana Benck, não posso tomar nenhuma decisão profissional sem agradecê-la, porque ultrapassa a posição de professora, é mestre, quase uma 
guru, um exemplo impecável de profissionalismo, ao professor Tiago Russomano e Lídia Bezerra, pela disponibilidade e apoio.

Ao meu marido, Erik Marques, um super, ultra, mega agradecimento. Se cada um que agradeço participou em partes do processo da construção desse trabalho, você esteve presente em cada um dos momentos, inclusive nos mais difíceis e estressantes. Seu companheirismo e compreensão e principalmente o seu apoio foram muito importantes durante esse período e a minha admiração por você só cresceu.

Aos meus amigos que respeitaram a minha ausência e me aturaram falando sem parar da minha pesquisa nos momentos em que conseguimos ter um tempinho. Aos meu atletas pela compreensão e apoio.

Agradeço ainda a equipe das escolas Jardim de Infância 603 do Recanto das Emas, em especial a Fabíola (sempre tão prestativa e alegre), e Centro de Ensino Fundamental 602 do Recanto das Emas, bem como aos responsáveis e as crianças que participaram e apoiaram a pesquisa.

A Deus por me permitir viver essa experiência inesquecível. 


\section{SUMÁRIO}

LISTA DE TABELAS $\ldots \ldots \ldots \ldots \ldots \ldots \ldots \ldots \ldots \ldots \ldots \ldots \ldots \ldots \ldots \ldots$

LISTA DE FIGURAS $\ldots \ldots \ldots \ldots \ldots \ldots \ldots \ldots \ldots \ldots \ldots \ldots \ldots \ldots \ldots$

LISTA DE SIGLAS, ABREVIAÇÕES E SÍMBOLOS $\ldots \ldots \ldots \ldots \ldots$ xii

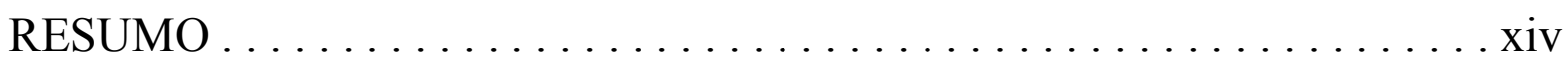

ABSTRACT $\ldots \ldots \ldots \ldots \ldots \ldots \ldots \ldots \ldots \ldots \ldots \ldots \ldots \ldots \ldots \ldots \ldots \ldots$

1. INTRODUÇÃ̃ $\ldots \ldots \ldots \ldots \ldots \ldots \ldots \ldots \ldots \ldots \ldots \ldots \ldots$

2. OBJETIVOS $\ldots \ldots \ldots \ldots \ldots \ldots \ldots \ldots \ldots \ldots \ldots \ldots \ldots \ldots$

2.1. Objetivo Geral $\ldots \ldots \ldots \ldots \ldots \ldots \ldots \ldots \ldots \ldots \ldots \ldots \ldots \ldots$

2.2. Objetivos Específicos $\ldots \ldots \ldots \ldots \ldots \ldots \ldots \ldots \ldots \ldots \ldots$

2.3. Hipóteses $\ldots \ldots \ldots \ldots \ldots \ldots \ldots \ldots \ldots \ldots \ldots \ldots \ldots \ldots \ldots \ldots$

3. REVISÃO DE LITERATURA $\ldots \ldots \ldots \ldots \ldots \ldots \ldots \ldots \ldots \ldots \ldots \ldots \ldots \ldots \ldots \ldots$

3.1. A Marcha Humana..$\ldots \ldots \ldots \ldots \ldots \ldots \ldots \ldots \ldots \ldots$

3.1.1. O Ciclo da Marcha Humana $\ldots \ldots \ldots \ldots \ldots \ldots \ldots \ldots$

3.1.2. A Assimetria da Marcha. ...................... 9

3.2. A Biomecânica do Correr . ......................

3.3. Desenvolvimento do Pé em Crianças ...................

3.4. Pressão Plantar .............................. 14

3.4.1. Avaliação da Pressão Plantar . . . . . . . . . . . . . . 15

3.4.2. Especificações do Sistema de Avaliação . . . . . . . . . . . . 17

3.4.3. Pressão Plantar Durante o Correr . . . . . . . . . . . . . 18

3.4.4. Pressão Plantar na Marcha de Crianças . . . . . . . . . . . . . 21 
3.4.5. Velocidade e Distribuição de Pressão Plantar . . . . . . . . . . 23

4. MATERIAL E MÉTODOS $\ldots \ldots \ldots \ldots \ldots \ldots \ldots \ldots \ldots \ldots \ldots$

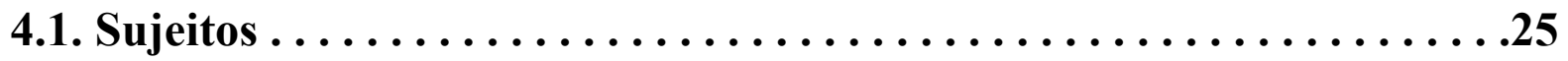

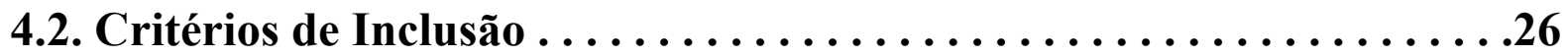

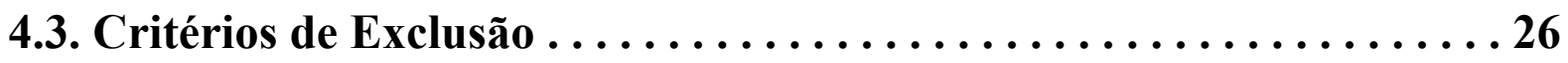

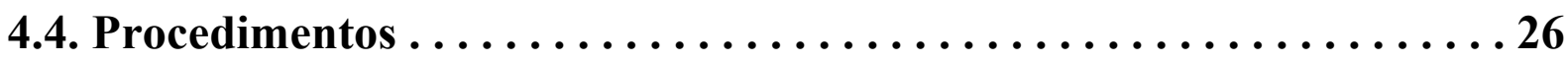

4.4.1. Seleção dos avaliados . . . . . . . . . . . . . . . . . . . 27

4.4.2. Avaliação Antropométrica . . . . . . . . . . . . . . . . .27

4.4.3. Avaliação Baropodométrica. . . . . . . . . . . . . . 28

4.5. Procedimentos Estatísticos. .................... 32

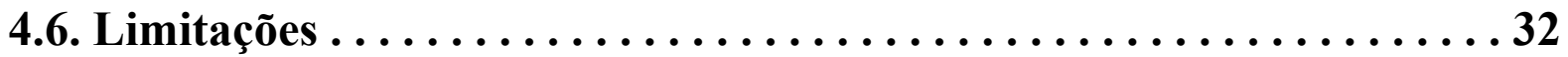

5. RESULTADOS. ........................... 34

5.1. Comparação da Pressão Plantar entre Avaliações 1 e $2 \ldots \ldots \ldots . . .34$

5.2. Comparações entre os Grupos .......................

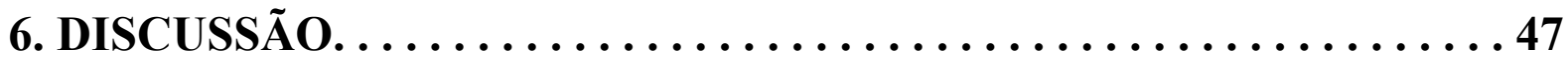

6.1. Distribuição de Pressão Plantar no Período de um Ano ......... 47

6.2. Distribuição de Pressão Plantar entre os Grupos Etários .........50

6.3. Avaliação entre o Pé Direito e o Pé Esquerdo ..............52

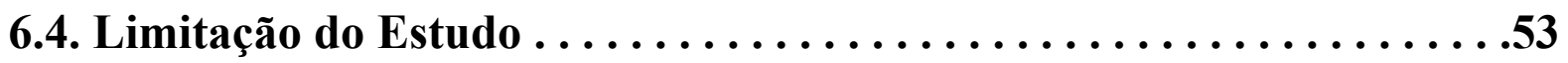

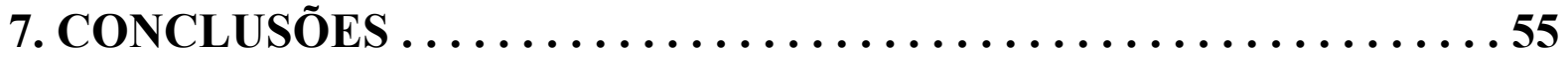

8. REFERÊNCIAS BIBLIOGRÁFICAS $\ldots \ldots \ldots \ldots \ldots \ldots \ldots \ldots$

ANEXO I ........................................ 65 
ANEXO II ................................ 67

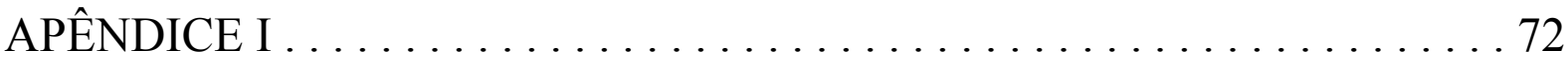

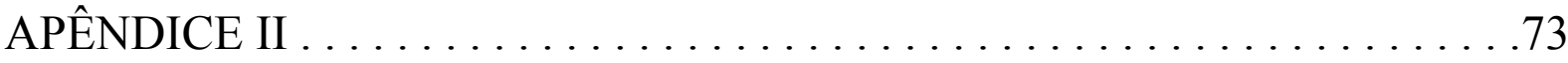

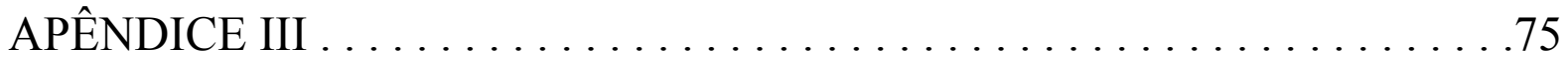




\section{LISTA DE TABELAS}

Tabela 1 - Comparação entre a avaliação 1 e a avaliação 2 para as variáveis massa, estatura e velocidade. . . . . . . . . . . . . . . . . . 34

Tabela 2 - Comparação entre a avaliação 1 e a avaliação 2 para as variáveis de pressão plantar. . . . . . . . . . . . . . . . . . . . . . . 36 


\section{LISTA DE FIGURAS}

Figura 1 - Esquema representativo das fases e subfases do ciclo de corrida. . .8

Figura 2 - Diferença entre a força de reação do solo vertical para um sujeito correndo em pisos duro e macio. . . . . . . . . . . . . . . . . . . 11

Figura 3 - Curva típica de pico de pressão. $\ldots \ldots \ldots \ldots \ldots \ldots \ldots \ldots$

Figura 4 - Plataforma de avaliação da DPP Emed ${ }^{\circledR}$ e representação do software utilizado pelo sistema Emed-AT (Novel, Alemanha). . . . . . . . . . . . 28

Figura 5 - Passarela de EVA, plataforma e posicionamento dos avaliados. . . 29

Figura 6 - Imagem gerada pelo software Emed/R (Novel, Alemanha) com a representação da divisão do pé em 5 regiões. . . . . . . . . . . . . 31

Figura 7 - Comparação entre os grupos etários para pico de pressão na avaliação 1 considerando o pé total e as diferentes regiões do pé. . . . . . . 38

Figura 8 - Comparação entre os grupos etários para pico de pressão na avaliação 2 considerando o pé total e as diferentes regiões do pé. . . . . . . 39

Figura 9 - Comparação entre os grupos etários para força máxima relativa na avaliação 1 considerando o pé total e as diferentes regiões do pé. . . . . . . 40

Figura 10 - Comparação entre os grupos etários para força máxima relativa na avaliação 2 considerando o pé total e as diferentes regiões do pé. . . . . . 41

Figura 11 - Comparação entre os grupos etários para tempo de contato relativo na avaliação 1 considerando o pé total e as diferentes regiões do pé. . . . . . 42

Figura 12 - Comparação entre os grupos etários para tempo de contato relativo na avaliação 2 considerando o pé total e as diferentes regiões do pé. . . . . . 43

Figura 13 - Comparação entre os grupos etários para área de contato na avaliação 1 considerando o pé total e as diferentes regiões do pé. . . . . . . 44 
Figura 14 - Comparação entre os grupos etários para área de contato na avaliação 2 considerando o pé total e as diferentes regiões do pé. . . . . . . . 45 


\section{LISTA DE SIGLAS, ABREVIAÇÕES E SÍMBOLOS}

\begin{tabular}{ll} 
a & Área \\
A1 & Avaliação 1 \\
A2 & Avaliação 2 \\
AC & Área de contato \\
cm & Centímetros \\
cm $^{2}$ & Centímetros quadrados \\
DPP & Distribuição de pressão plantar \\
EVA & Etinil Vinil Acetato \\
F & Força \\
Fmáx & Força máxima \\
Fmáx\% & Força máxima relativa \\
G4 & Grupo com 4 anos na Avaliação 1 \\
G5 & Grupo com 5 anos na Avaliação 1 \\
G6 & Grupo com 6 anos na Avaliação 1 \\
Hz & Hertz \\
IMC & Índice de Massa Corporal \\
kg & Quilograma \\
kPa & Quilopascal \\
MPa & Metros \\
\hline Milímetros
\end{tabular}




$\begin{array}{ll}\text { ms } & \text { Milisegundos } \\ \mathrm{N} & \text { Newton } \\ \mathrm{p} & \text { Pressão } \\ \mathrm{Pa} & \text { Pascal } \\ \mathrm{PC} & \text { Peso corporal } \\ \mathrm{PP} & \text { Pico de pressão } \\ \mathrm{S} & \text { Segundo } \\ \text { TC } & \text { Tempo de contato } \\ \text { TC\% } & \text { Tempo de contato relativo }\end{array}$




\title{
RESUMO
}

\section{DISTRIBUIÇÃO DE PRESSÃO PLANTAR DURANTE O CORRER EM CRIANÇAS}

\author{
Autora: Tainá Neves Vieira \\ Orientadora: Ana Cristina de David
}

\begin{abstract}
A descrição de valores normativos de distribuição de pressão plantar auxiliam e orientam profissionais de diversas áreas, contudo dados durante o correr em crianças não estão disponíveis. Objetivo: Descrever as possíveis mudanças no comportamento da distribuição da pressão plantar durante o correr em crianças de 4 a 6 anos de idade no período de um ano. Métodos: Pesquisa longitudinal que avaliou 28 crianças entre 4 e 6 anos de idade antes e após o período de um ano. As crianças foram divididas em três grupos: G4, G5 e G6, com 4, 5 e 6 anos respectivamente na avaliação 1. A distribuição de pressão plantar foi avaliada durante o correr em velocidade auto-selecionada sobre a plataforma Emed/Novel. A área de contato, o pico de pressão, o tempo de contato relativo e a força máxima relativa foram as variáveis registradas. Os sujeitos correram descalços e o pé foi dividido em cinco regiões: retropé, mediopé, antepé, hálux e dedos. Resultados: O comprimento do pé aumentou para todos os grupos avaliados no período de um ano. A área da contato e o pico de pressão também aumentaram considerando o pé total e as regiões do pé, com exceção do mediopé. Houve um tendência a diminuição do pico de pressão e força máxima relativa na região do retropé e aumento no pé total e antepé. Não houve efeito significativo do fator idade na maioria das variáveis de DPP. As principais diferenças entre os grupos ocorreram entre o G6 e os demais grupos,
\end{abstract}


com a tendência de valores médios significativamente maiores para os avaliados do G6 tanto na avaliação 1 como na avaliação 2. Não houve diferenças nos valores de DPP entre o pé direito e esquerdo durante o correr. Conclusão: Os resultados desse estudo indicam que o desenvolvimento do pé e o padrão do correr parecem não terem atingido a maturação completa aos 6 anos de idade. Tais dados podem servir de referência para o desenvolvimento de produtos, como calçados e próteses, bem como referência para o acompanhamento do desenvolvimento típico e atípico em crianças.

Palavras-chave: Crianças, Distribuição de Pressão Plantar, Correr. 


\begin{abstract}
PLANTAR PRESSURE DISTRIBUTION DURING RUNNING IN CHILDREN
\end{abstract}

\title{
Author: Taina Vieira Neves \\ Adviser: Ana Cristina David
}

The description of normative values in plantar pressure distribution help and guide professionals from different areas, but data during running in children are not available. Objective: Describe the possible changes in the plantar pressure distribution during running in children with 4 to 6 years old in one year. Methods: This longitudinal research evaluated 28 children between 4 and 6 years old before and after a period of one year. The children were divided into three groups: 4-5 years old, 5-6 years old and 6-7 years old. The plantar pressure distribution was evaluated during running at self-selected speed on the platform Emed/Novel and contact area, peak pressure, relative contact time and relative maximum force were recorded. The subjects ran barefoot and the foot was divided into five regions: hindfoot, midfoot, forefoot, hallux, toes. Results: Foot length increased for all groups evaluated in one year. Contact area and peak pressure increased considering the total foot and the foot regions, with the exception of midfoot. There was no significant effect of age in plantar pressure distribution. The main differences between the groups were among the group 67 years and the other groups, with the trend of significantly higher mean values for group 6-7 years in the evaluation 1 and in the evaluation 2. There are no differences between the right and left foot. Conclusion: The contact area increased over the period of one year in various regions of the foot and total foot for the three groups, the midfoot did not differ in the period of one year. There 
was a tendency to decrease in peak pressure and relative maximal force in the hindfoot and increase in total foot and forefoot. The main differences in plantar pressure distribution between groups were among the group of six years and the other groups, with a trend towards higher plantar loads for the group of 6 years in total foot, forefoot, hallux and toes. The growth and development of the foot seems to be incomplete at 6 years old. There is no difference between the results obtained in attempts with the right foot and the left foot.

Keywords: Children, Plantar Pressure Distribution, Running. 


\section{INTRODUÇÃO}

A marcha é um movimento fundamental ao ser humano. Duas pessoas não se locomovem de forma idêntica, contudo, alguns padrões podem ser identificados. De acordo com Martin e Sanderson (1), o correr é uma atividade motora altamente complexa que incorpora a ação de vários níveis do sistema nervoso, envolvendo a contribuição de grande parte dos músculos do corpo e pode ser definida como um movimento alternado e cíclico dos membros inferiores.

Apesar de serem complexos, os padrões do correr começam a se desenvolver cedo na infância. A criança tenta correr entre os 13 e 18 meses de idade, ainda sem fase de vôo, a fase aérea é observada por volta do segundo e terceiro ano de vida $(2,3)$. Isso ocorre devido as rápidas transformações do sistema musculoesquelético e do sistema nervoso central sofridas na infância. Assim, a aquisição de habilidades motoras fundamentais, como o andar e correr, depende dos processos de maturação biológica e crescimento, bem como das experiências e repertório motor vivenciado pela criança. Vários fatores podem afetar esses processos, como o desenvolvimento atípico devido à doenças e lesões.

A variável distribuição de pressão plantar (DPP) tem sido recentemente relatada na literatura como indicadora do padrão de carga imposta ao sistema musculoesquelético. As forças musculares produzidas para gerar os movimentos da locomoção humana causam cargas nas plantas dos pés quando em contato com o solo. Essas cargas representam uma boa estimativa da eficiência mecânica do movimento e podem desencadear modificações na funcionalidade do pé, originando uma alteração na forma como a pressão é distribuída. Importantes estudos sobre o desenvolvimento da estrutura anatômica e fisiológica do pé e a DPP têm sido realizados com a população infantil, em 
diferentes faixas etárias, na posição ereta quieta e durante o andar $(3,4)$. Esses dados são importantes para compreensão de como ocorre o desenvolvimento da locomoção humana e servem, também, como referência para intervenções no caso da marcha patológica (5).

Estudos recentes $(3,6)$ buscaram encontrar valores normativos para caracterizar o desenvolvimento do pé da criança saudável e verificar os padrões de distribuição plantar, observando valores de pressão, força e área de contato do pé, e analisando a relação dessas grandezas com diversas variáveis, como a forma do pé, a estatura e a massa corporal do indivíduo e o gênero.

No estudo de Bosch et al. (3), 90 crianças alemãs foram acompanhadas dos 15 aos 63 meses em 11 encontros e feitas medições estáticas, para verificar as mudanças na formação do pé, e dinâmicas, durante o caminhar, para verificar a distribuição da carga no pé. Os dados apresentados mostraram um aumento do pico de pressão em todas as subdivisões da área do pé e também um crescimento de $92 \%$ na área total do pé. Houve decréscimo de 9\% ao ano apenas da área de contato na região do médio-pé. Na comparação entre os gêneros, os meninos tiveram valores maiores nos dados relacionados à largura do médio-pé e também ao índice de formação do pé.

Estudos sobre o padrão biomecânico do andar em crianças abaixo de 10 anos mostram que as cargas plantares aumentam em até 190\% e apresentam assimetria nos primeiros anos de marcha independente (6). O correr, por sua vez, impõe maiores cargas mecânicas ao sistema musculoesquelético que o andar, gerando maiores demandas do sistema locomotor e deixando-o mais suscetível à lesões.

Informações a respeito de como essas cargas afetam as forças que devem ser sustentadas pelo pé são importantes na avaliação do desenvolvimento motor e para o desenvolvimento de produtos, como calçados infantis (3). Dados de referência ou normativos sobre o correr em crianças de diferentes faixas etárias 
tem papel fundamental na avaliação de disfunções e no desenvolvimento. No entanto, não foram encontrados estudos sobre o desenvolvimento da distribuição da pressão plantar durante o correr em crianças. 


\section{OBJETIVOS}

\subsection{Objetivo Geral}

Descrever as possíveis mudanças no comportamento da distribuição da pressão plantar durante o correr em crianças de 4 a 6 anos de idade no período de um ano.

\subsection{Objetivos Específicos}

Descrever os valores de pressão plantar (pico de pressão, força máxima relativa, área de contato e tempo de contato relativo) no correr de crianças de 4 a 6 anos de idade no período de um ano;

Comparar as variáveis de pressão plantar no correr entre as diferentes faixas etárias;

Descrever os valores de comprimento do pé e índice de arco plantar dinâmico durante o correr de crianças de 4 a 6 anos de idade;

Verificar se há diferença entre o pé direito e o pé esquerdo para as variáveis de pressão plantar no correr em cada faixa etária;

\subsection{Hipóteses}

Os valores de pressão plantar (pico de pressão, força máxima normalizada, área de contato e tempo de contato) no correr aumentam no período de um ano;

Os valores de pressão plantar no correr aumentam com o aumento da idade; 
Não há diferença entre os valores de pressão plantar do pé direito e do pé esquerdo durante o correr. 


\section{REVISÃO DE LITERATURA}

\subsection{A Marcha Humana}

A marcha humana é um processo de locomoção no qual o corpo se move através do espaço, caracterizado por uma sequência de múltiplos eventos rápidos e complexos. Ao caminhar ou correr há um padrão básico de deslocamento rítmico das partes do corpo que mantém o indivíduo em constante progresso para diante, obtido por meio de movimentos coordenados dos segmentos corporais aproveitando a vantagem de uma interação de forças internas e externas, acompanhado da ação do sistema neuromusculoesquelético $(7,8)$. A marcha pode ser descrita como uma progressão translacional do corpo como um todo, produzida por movimentos rotatórios de segmentos corporais coordenados. A marcha normal é rítmica e caracterizada pela alternância entre movimentos propulsivos e retropropulsivos das extremidades inferiores (9).

A documentação da marcha humana iniciou-se a partir do final do século XIX. No século XX, com os avanços da tecnologia, vários centros desenvolveram laboratórios para analisar os movimentos humanos. Várias publicações foram e continuam sendo produzidas sobre esse assunto e o avanço dos estudos nos últimos anos foi tão significativo que indicar um tratamento para uma deficiência de marcha exige uma análise cuidadosa da locomoção (7). A quantificação do movimento acrescentou muitas vantagens à pesquisa e ao entendimento da marcha e, tanto na locomoção saudável quanto patológica, é possível obter medições importantes.

A análise da marcha consiste na mensuração, descrição e avaliação sistemática de dados que caracterizam a locomoção humana e tem fundamental relevância no estudo e no tratamento de patologias que envolvem o aparelho locomotor (7). Três níveis distintos de variáveis físicas são englobados pela análise da locomoção: dados cinemáticos, que descrevem a geometria do 
movimento; dados cinéticos, que constituem as forças e os momentos exercidos na interação corporal; e alterações bioelétricas, associadas à atividade do músculo esquelético. Em conjunto, estes dados promovem um retrato do fenômeno da marcha (10).

A compreensão do movimento humano do ponto de vista biomecânico é extremamente importante para várias áreas do conhecimento, entre elas a robótica, o desporto, a fisioterapia e a medicina (11). A medição do movimento humano pode promover informação relevante para a indústria biomédica, militar e industrias de consumo. Trabalhos incorporando a biologia e a engenharia, por exemplo, simulam a locomoção de forma computadorizada e comparam os resultados com dados reais, com o objetivo de resolver problemas como o design artificial de músculos esqueléticos e a construção de próteses inteligentes (10).

Os dados obtidos relativos ao movimento corporal também podem ser importantes do ponto de vista do desporto, para correção de erros técnicos e otimização do processo de formação.

A análise e quantificação da marcha tem permitido um maior conhecimento dos efeitos de patologias, da maturação e desenvolvimento, e da capacidade de aquisição de movimentos humanos selecionados (12). Este tipo de medição revela características da marcha que não são acessíveis através de observação visual ou outros métodos clínicos. O campo de reabilitação médica, ou seja, o que se relaciona com construção de próteses e órteses para extremidades em patologias e traumas do sistema locomotor, talvez seja o campo de aplicação mais promissor. 


\subsubsection{O Ciclo da Marcha Humana}

A unidade básica de medida da marcha é o ciclo da marcha, que inclui as atividades ocorridas desde quando um pé entra em contato com o solo até quando o mesmo pé toca o solo novamente. Durante um ciclo, cada extremidade passa por duas fases, uma fase de apoio e uma fase de balanço. A fase de apoio inicia-se no instante em que ocorre o contato inicial com o solo e continua enquanto o pé estiver em contato com o mesmo. A fase de balanço inicia quando o membro inferior deixa de tocar o solo (take off) e termina antes do ataque ao solo do mesmo membro $(9,13)$.

Com o aumento da velocidade de locomoção a fase de apoio de ambos os pés dá lugar a dois períodos de flutuação dupla, no início e no final da fase de balanço. Essa transição acontece voluntariamente no homem a uma velocidade de locomoção de aproximadamente $2,3 \mathrm{~m} / \mathrm{s}$ e $2,5 \mathrm{~m} / \mathrm{s}$, distinguindo o caminhar do correr (14). Existem ainda diversas diferenças entre o padrão de movimento de caminhar e correr, mas este estudo ocupa-se da análise do movimento de locomoção durante o correr.

Um ciclo de marcha para o correr e as fases de apoio e de balanço estão representadas na Figura 1.

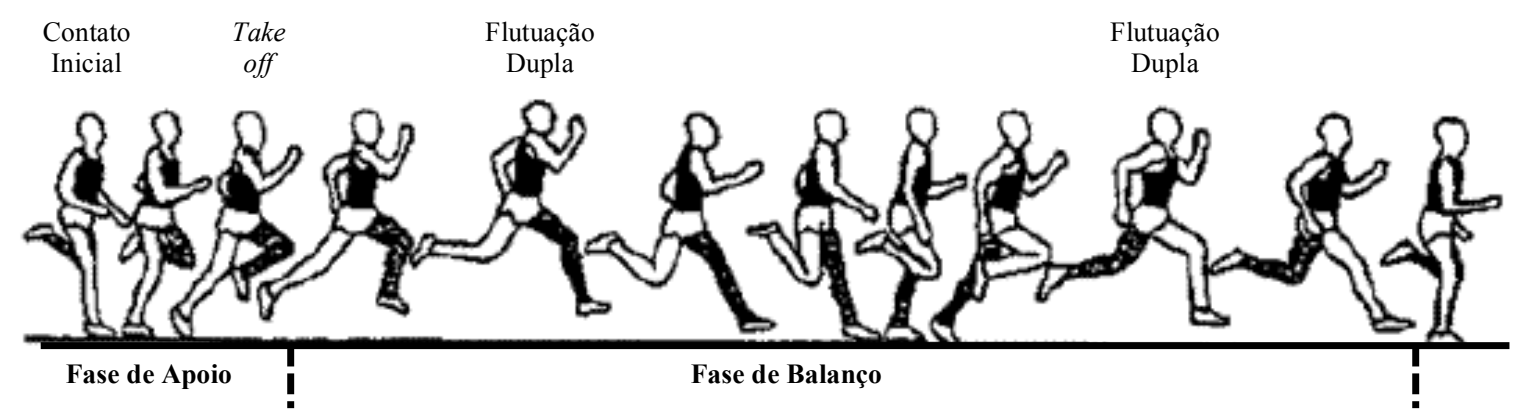

Figura 1 - Esquema representativo das fases e subfases do ciclo de corrida. (15) 
A fase de apoio permite a progressão enquanto mantém a estabilidade de sustentação do peso do corpo, enquanto a fase de balanço tem por características o levantamento do pé do solo, o avanço do membro no espaço e preparação para o próximo apoio (7).

\subsubsection{A Assimetria da Marcha}

A assimetria da marcha pode ser definida como a falta do acordo entre os membros inferiores (16) e pode ter diferentes causas, como diferença no comprimento das estruturas ósseas ou pode ser resultado de alterações mecânicas nos membros inferiores e até mesmo patologias do sistema locomotor (17). Alterações na dinâmica da locomoção de sujeitos com patologias e diferenças no comprimento de membros inferiores têm sido descritas pela literatura, e análise biomecânica da marcha tem se mostrado um método eficiente em detectar assimetrias entre os membros inferiores $(18,19)$.

Estudos que avaliam o caminhar em crianças saudáveis não encontraram diferenças significativas entre os dados de pressão plantar dos pés direito e esquerdo. A simetria durante o caminhar de crianças foi relatada como invariante em velocidades auto selecionadas ou velocidade livre $(6,20)$. Esta informação é importante, uma vez que pode ser utilizado por médicos e investigadores para avaliar a marcha. Mas pouco se sabe sobre a simetria do padrão do correr de uma criança.

\subsection{A Biomecânica do Correr}

A fase de apoio do ciclo de corrida foi muito estudada e pode ser dividida em duas fases funcionais: a fase de absorção ou fase excêntrica da corrida, primeira metade da fase de apoio e a fase de propulsão ou fase concêntrica, segunda metade da fase de apoio. 
As articulações dos membros inferiores e, principalmente, os músculos que as envolvem, têm a função de auxiliar na absorção da onda de energia mecânica proveniente do contato do pé com o solo (21). As forças de impacto atuantes durante o correr são determinadas, principalmente, pela geometria de colocação do pé no solo e seus reflexos no membro inferior (articulações do joelho e quadril), pela velocidade do pé no contato inicial e pelas propriedades dos materiais dos pisos de contato $(22,23)$. Quando o pé toca o solo já existe o movimento de pronação do pé (24), mecanismo de melhora da atenuação do impacto decorrente da acomodação do pé a superfície.

A força de impacto desempenha papel relevante durante a marcha e na corrida pode chegar a 5 vezes o peso corporal, dependendo da velocidade, em um período de tempo de 10 a $30 \mathrm{~ms}$ (25). O aparelho locomotor saudável desenvolve estratégias de atenuação das forças de impacto para que essas não cheguem as articulações superiores com a mesma magnitude. Para Feehery (26), $90 \%$ das forças de impacto produzidas durante o correr são atenuadas da tíbia até a cabeça em 10 ms. Os músculos são mais ativos na antecipação e logo após o contato inicial. A contração muscular é aparentemente mais importante no momento de preparação e no ato de sair do chão, isto porque este pequeno período de tempo é insuficiente até mesmo para mecanismos reflexos serem ativados com o intuito de proteção. No momento do contato com o solo ocorre o pico de impacto ou pico passivo e quando as estruturas ativas (músculos, fáscias e tendões) não conseguem de forma eficiente absorver este impacto, então parte dele é suportado diretamente pelas estruturas passivas (ossos e estruturas articulares). Após este primeiro contato do calcanhar com o solo, ocorrerá a atenuação do impacto de forma ativa, desacelerando o corpo contra o colapso com o solo (13).

A análise das forças de reação do solo e de pressão plantar são as principais formas de avaliar as cargas nos membros inferiores, identificando 
como o membro em contato com o solo recebe as cargas externas e como as forças geradas pelos músculos promovem a sequência de propulsão após o recebimento da carga. A Figura 2 ilustra a força de reação do solo vertical durante o correr em diferentes pisos.

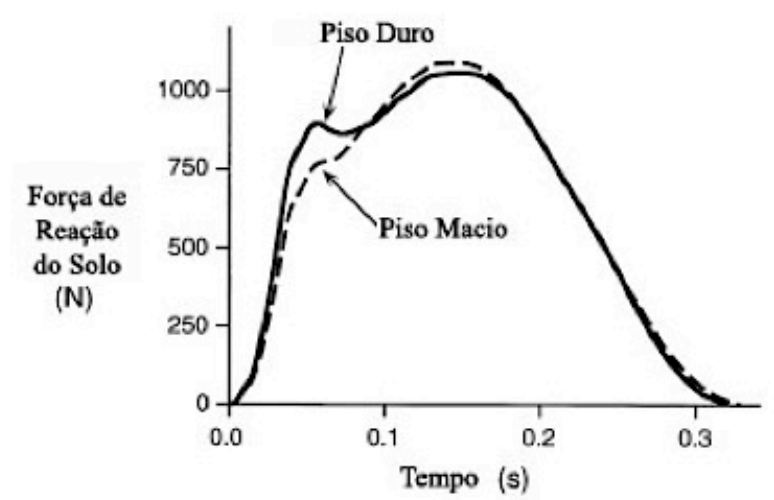

Figura 2 - Diferença entre a força de reação do solo vertical para um sujeito correndo em pisos duro e macio, houve uma considerável redução no pico de impacto inicial no piso macio (adaptado de Ferris et al.). (27)

O padrão do correr com o contato inicial feito pelo retropé apresenta dois picos verticais na FRS segundo Nigg (22), o primeiro é denominado pico de impacto, onde a atividade muscular não consegue atuar como atenuador da magnitude em função do pouco tempo para ativação, e o segundo, denominado pico ativo, já é influenciado pela atividade muscular durante o apoio. A forma da corrida, bem como o tipo de calçado e piso e a velocidade de deslocamento podem alterar a apresentação do pico ativo $(13,22,28,29)$.

Gerlach et al. (30) avaliaram a força de reação do solo vertical em corredoras nas velocidades em $2,7 \mathrm{~m} / \mathrm{s}$ e $4,5 \mathrm{~m} / \mathrm{s}$ e observaram picos de impacto de 1,96 vezes o peso corporal (PC). Kyrolainen et al. (31) encontraram valores da ordem de 2,5 PC para o pico de impacto em homens atletas de elite. As forças antero-posteriores mostram um momento de desaceleração durante a 
primeira metade da fase de apoio, quando ocorre a diminuição da velocidade. Após esta fase de desaceleração, inicia-se a fase de propulsão e a velocidade volta a aumentar novamente. Esta diferença de velocidade, de cerca de 5\%, entre a frenagem pelo retropé e a propulsão pelo antepé, reflete a propulsão extra necessária para sobrepor a resistência do ar durante a fase de voo $(28,30)$.

Segundo um estudo realizado por Eils et al. (32) com sujeitos calçando chuteiras de futebol, a pressão plantar encontrada durante a corrida a $4 \mathrm{~m} / \mathrm{s}$ quando o contato é realizado com o retropé é $300 \mathrm{kPa}$, com o antepé medial 415 $\mathrm{kPa}$ e $348 \mathrm{kPa}$ no hálux. Valores semelhantes foram encontrados por Weist et al (33).

Durante o correr, o pico de energia potencial e cinética é no meio do balanço. À medida que o centro de massa se desloca em direção ao solo, a energia potencial diminui. À medida em que o pé entra em contato com o solo, a energia cinética diminui. Grande parte da energia potencial e cinética é convertida em energia potencial elástica e armazenada nos músculos, tendões, e ligamentos. Durante a fase de geração, o centro de massa acelera e ambas, energia potencial e cinética, aumentam. A energia para este movimento é fornecida pela contração ativa dos músculos e a liberação da energia potencial elástica armazenada nos ligamentos e tendões (13).

É geralmente aceito que um dos fatores determinantes mais importantes na maneira pela qual o individuo se move é a maximização da eficiência energética. Segundo algumas pesquisas que relacionam a análise cinética e cinemática da marcha com a análise metabólica, o correr exige uma alta demanda de energia, podendo ser mantida sem a diminuição da velocidade por um longo tempo ou por um curto tempo quando se corre a altas velocidades. Mas não existe tal relação para a corrida de velocidade e o custo de energia. O custo de oxigênio muda pouco em uma ampla gama de velocidades de corrida escolhidas. Economia de movimento é, obviamente, mantida por mecanismos 
que permanecem evasivo, mas, sem dúvida, incluem opções de comprimento do passo/cadência, a velocidade de encurtamento muscular, e as fontes de produção de energia mecânica $(13,34,35)$.

\subsection{Desenvolvimento do Pé em Crianças}

Os pés de crianças apresentam diferenças típicas em tamanho e forma, o padrão da marcha, como a forma do pé, muda rapidamente em comparação com os adultos e, especialmente, entre as próprias crianças $(3,6)$.

O desenvolvimento do pé da criança é fortemente influenciado pela fase na qual a criança começa a ficar de pé e pelo início da habilidade de caminhar. Uma grande variedade de formas do pé é considerada típica nesta idade e essa variabilidade diminui à medida que a criança cresce. A ossificação do pé acontece de forma contínua até a idade de cinco anos e durante os primeiros 4 ou 5 anos de vida há gordura preenchendo o arco longitudinal do pé, aumentando a área de contato e auxiliando na amortização e absorção das cargas impostas ao sistema musculoesquelético. O arco longitudinal se desenvolve de forma contínua até os 6 anos de idade $(3,36-38)$.

Além das alterações nos tecidos dos ossos, o calcanhar sofre uma remodelação durante o crescimento que suporta o desenvolvimento do arco longitudinal e é causada por uma combinação de carga estática e atividade muscular (37).

Cinquenta por cento do comprimento final do pé já é atingido com a idade de 12-18 meses, enquanto a velocidade de crescimento diminui rapidamente até a idade de 5 anos. Entre 5 e 12 anos de idade, os pés das meninas crescem em média $0,9 \mathrm{~cm}$ por ano e nos meninos esse período dura até a idade de 14 anos (3, $6,39)$.

A velocidade do desenvolvimento do pé varia entre os indivíduos e há também uma grande variabilidade inter-individuo para o padrão de marcha 
durante a infância. Portanto, uma diferenciação entre as características fisiológicas e patológicas pode ser extremamente difícil. A avaliação dos pés das crianças em ambientes clínicos poderia ser facilitada pelo conhecimento de padrões de pressão plantar dinâmicos (40).

\subsection{Pressão Plantar}

O pé humano é uma estrutura biomecânica de formação complexa e, graças às suas caraterísticas, proporciona ao corpo humano uma base estável que confere de forma eficiente o suporte e o equilíbrio apoio durante o processo da marcha. O pé e o tornozelo fornecem tanto o apoio como a flexibilidade necessários para rolamento e deslocamento de peso durante a marcha e outras atividades funcionais (41-43).

O método mais usado para avaliar a interação do pé e da superfície de suporte é a avaliação da forças de reação do solo utilizando plataformas de força. Embora a plataforma de força forneça informações valiosas sobre as componentes verticais e horizontais da força de reação do solo, é proporcionada pouca informação sobre a forma como a superfície plantar do pé é carregada com respeito à superfície de suporte. Os sistemas de medição de pressão plantar fornecem as informações sobre a função do pé e tornozelo, além de apresentarem um elevado grau de portabilidade, permitindo a utilização em vários locais.

A Força, quando medida utilizando uma plataforma de força, é o resultado líquido dos três componentes de reação do solo (antero-posterior, médio-lateral, vertical) ou força resultante agindo sobre o pé. A Pressão (p) é definida como a força (F) por unidade de superfície (A), isto é $p=\frac{F}{A}$ (44). A Unidade Internacional de força é o newton (N), e a de pressão é o pascal (Pa). Um pascal é definido como a pressão sentida quando a força de $1 \mathrm{~N}$ é distribuído sobre uma área de $1 \mathrm{~m}^{2}$ (45). Valores de pressão são geralmente comunicados em 
quilopascal $(\mathrm{kPa})$ ou megapascal $(\mathrm{MPa})$.

Ao avaliar a pressão plantar, um sensor discreto ou uma matriz de sensores múltiplos é utilizado para medir a força que atua sobre cada um dos sensores, enquanto o pé está em contato com a superfície. A magnitude da pressão é então determinada dividindo a força medida pela área conhecida do sensor ou sensores ativados enquanto o pé estava em contato com a superfície de suporte (46).

Pressões plantares podem ser medidas usando uma variedade de instrumentos, incluindo resistores sensíveis a força, hidrocélulas, microcápsulas, aparelhos de projeção, pedoscópios, transdutores de capacitância e deflexão de luz crítica. Neste estudo, um sistema transdutor de capacitância foi utilizado, composto por duas chapas feitas de um material condutor separadas por uma camada não condutora ou isolante. O transdutor armazena uma carga elétrica, e as duas placas são comprimidas quando a força é aplicada, fazendo com que a distância entre as placas diminua. À medida que a distância entre as placas diminui, a capacitância aumenta e a alteração resultante em tensão é medida (47). Sistemas de medição de pressão usando transdutores de capacitância utiliza uma curva de calibração que é desenvolvido para cada sensor na matriz e possibilita a avaliação quantitativa da pressão.

Os dados obtidos a partir de uma avaliação da pressão plantar podem ser usados para a avaliação e tratamento de pacientes com uma ampla variedade de deficiências nos pés associados a distúrbios neurológicos e musculoesqueléticos, o que pode afetar tanto adultos como crianças. Quando os valores de pressão plantar são determinados atípicos, a informação pode ser usada para modificar o programa de um paciente por meio de alterações no tipo de calçado, órteses, programas de exercícios e restrições no valor de sustentação de peso. As informações também são úteis para outras atividades que envolvam a relação entre a pressão plantar e a postura da extremidade inferior, como em esportes e 
atividades funcionais (46).

\subsubsection{Avaliação da Pressão Plantar}

A Baropodometria é o estudo das cargas plantares e por consequência o estudo da postura. A análise baropodométrica permite avaliar e mensurar a distribuição da pressão plantar, tanto em situações estáticas quanto em situações dinâmicas, como na marcha (48). Entre as variáveis de distribuição de pressão plantar mais utilizadas estão o pico de pressão, força máxima, tempo de contato e área de contato.

O Pico de Pressão (PP) representa o maior valor de pressão registrada por cada sensor durante toda a fase de apoio (Figura 3). Na análise da pressão plantar o pico de pressão é um dos parâmetros cujo estudo é cada vez mais recorrente. Devido ao seu comportamento peculiar, esse parâmetro permite retirar conclusões cruciais para a prevenção, diagnóstico e tratamento de diversas patologias e deformidades plantares (5).

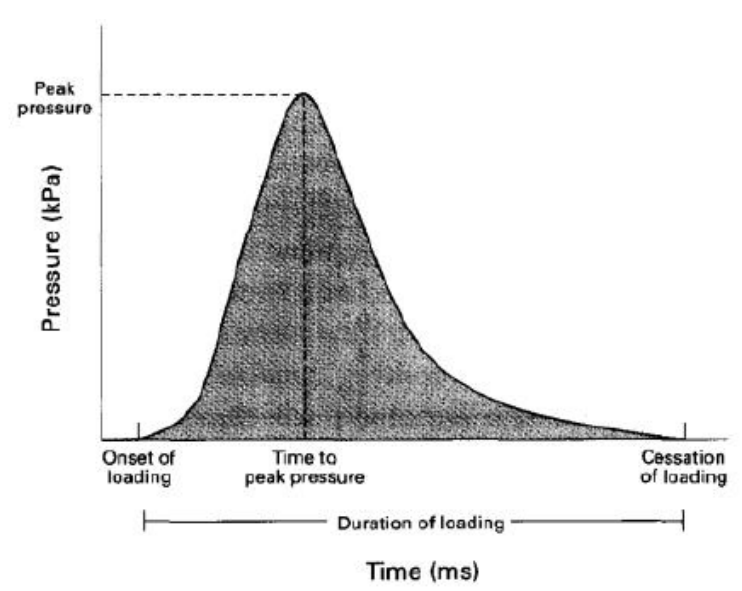

Figura 3 - Curva típica de pico de pressão (retirado de Rosenbaum e Becker, 1997).

A Força Máxima (Fmáx) corresponde ao somatório da força mensurada 
em cada sensor da plataforma. A Força Máxima Normalizada (Fmáx\%) corresponde ao somatório da força mensurada em cada sensor da plataforma normalizado pelo peso corporal do avaliado (5).

O Tempo de Contato (TC) corresponde ao tempo em que a superfície do pé mantém contato com a plataforma em milissegundos (5).

A Área de Contato (AC) é determinada pela soma da área de todos os sensores sobrecarregados pela superfície plantar e tem sido reconhecida como um parâmetro útil na análise da distribuição da pressão plantar (5).

\subsubsection{Especificações do Sistema de Avaliação}

A plataforma de pressão plantar apresenta algumas vantagens em relação a palmilha. O valor da força medida pelo sensor da plataforma e utilizado no cálculo da pressão é uma força normal ou uma força que é perpendicular à superfície do sensor. Quando uma palmilha de sensores é colocada dentro de um sapato, no entanto, a força normal apenas pode ser considerada força vertical durante a parte da fase de apoio na qual todo o pé está em contato com a superfície de suporte $(47,49)$. A resolução da plataforma, geralmente, é mais elevada. Em contra partida a intenção de pisar na área sensível da plataforma por parte do avaliado se apresenta como um dos seus problemas. O sujeito pode alterar o padrão de marcha para colocar o pé em contato com o plataforma (50). As palmilhas são especialmente importante quando se avalia o efeito do calçado.

Algumas especificações devem ser consideradas ao escolher um sistema de medição para pressões incluindo a resolução, a frequência de amostragem e a confiabilidade.

A Resolução refere-se ao tamanho e número de sensores utilizados no sistema. Quanto maior for a resolução do sistema, maior será o número de sensores. O tamanho do sensor também é importante, a força aplicada a um 
sensor grande não irá proporcionar a mesma leitura de pressão porque a resolução espacial do sistema não é suficientemente elevada. Considerando a variação anatômica no tamanho das cabeças dos metatarsos, hálux, e dedos do pé com base no tamanho do pé, a resolução do sistema de medição de pressão torna-se uma consideração importante para o pesquisador e ainda mais crítica quando se avalia a pressão plantar em crianças com tamanho dos pés pequenos (44).

A Frequência de amostragem é um fator importante na determinação da resolução temporal do sistema. A frequência de amostragem é o número de amostras medidas por cada sensor por segundo, registada em ciclos por segundo ou Hertz (44). A maioria dos instrumentos comercialmente disponíveis oferece taxas de amostragem entre 50 e $100 \mathrm{~Hz}$. Para atividades com maior velocidade frequências de amostragem de $200 \mathrm{~Hz}$ ou superior são, muitas vezes, necessárias (51).

A Confiabilidade das medidas obtidas com o sensor de pressão são fundamentais para uma medição precisa. Durante o caminhar, 3 a 5 tentativas aumentam a confiabilidade da medição de pressão, embora a replicabilidade de $100 \%$ não possa ser esperada devido às diferenças inerentes em cada tentativa (52).

\subsubsection{Pressão Plantar Durante o Correr}

Em um quilômetro de corrida cerca de 700 fases de apoio são realizadas (52). Assim, fase de apoio tem recebido atenção dos pesquisadores porque é durante o contato com o chão que as forças de reação do solo são geradas, pela soma do peso corporal e todas as forças que aceleram e/ou desaceleram a massa corporal. Dessa forma a DPP e as cargas plantares são importantes fatores na investigação de patologias de tornozelo e pé (53). 
A estrutura anatômica e biomecânica dos ossos e articulações do pé e tornozelo influenciam diretamente a DPP. Alguns artigos de revisão sobre a biomecânica do pé e tornozelo examinaram a mecânica normal e patológica do movimento do pé durante o correr $(13,40,54)$. O movimento do tornozelo no plano sagital é acompanhado pela rotação no plano transversal e de rotação do pé em torno do seu eixo mais longo, devido à orientação oblíqua da articulação do tornozelo. Durante a marcha, quando o pé é fixado ao solo, a dorsiflexão do tornozelo causa a rotação interna da tíbia e pronação do pé. No contato inicial, o retropé é tipicamente invertido. Uma pronação então ocorre quando o membro é carregado durante a fase de absorção. A pronação desbloqueia a articulação tarsal transversa aumentando a flexibilidade do pé permitindo que funcione de forma mais eficaz como um amortecedor. O pico de pronação ocorre normalmente em $40 \%$ da fase de apoio. O pé então começa a supinação e atinge uma posição neutra, a 70\% do apoio. A articulação tarsal transversa é, então, bloqueada. A fase de geração foi atingida e o pé é agora mais rígido, o que lhe permite agir de forma mais eficaz como uma alavanca para take off.

A maior parte da literatura que analisa a DPP durante o correr lida com indivíduos adultos, geralmente atletas corredores de longa distância. $\mathrm{O}$ enfoque dado nos estudos é na prevenção de lesões crônicas e os possíveis riscos relacionados a lesões $(53,55-58)$.

Fatores biomecânicos como a força máxima e o pico de pressão podem desenvolver um papel importante na prevenção, na detecção de lesões e no planejamento de reabilitação após uma lesão (55). O aumento da pressão plantar tem sido relacionado à lesão nos metatarsos em fundistas, fenômeno que pode ser explicado pelo aumento do pico de pressão sobre os ossos metatarsais durante o correr (58). A mesma relação entre a pressão plantar e lesão nos metatarsos foi encontrada para corredores adolescentes (59, 60). Apesar do grande número de adolescente que praticam e que se lesionam durante o correr, 
existem poucos estudos que avaliam a pressão plantar durante o correr em jovens atletas $(57,61)$.

Algumas variáveis têm efeito sobre as forças de impacto, incluindo o tipo de pé e de pisada, a velocidade do centro de massa no contato, a massa efetiva do corpo no contato, a área de contato e as propriedades do material dos elementos de amortecimento, tais como, o material e o tipo de calçado, e a superfície de contato $(13,25,53,55-57,61)$. As forças de impacto variam em magnitude de aproximadamente 1,5 a 5 vezes o peso corporal por um período muito curto de tempo. A magnitude da força de impacto durante o correr é determinada por fatores que antecedem o contato do pé no solo, como a velocidade e a geometria do pouso (25).

Sendo assim, o correr pode ser mais prejudicial no momento em que o pé colide com o chão (62). Esta colisão do pé com o solo pode ocorrer de diferentes formas, sendo: (I) retropé, em que o contato inicial é feita em algum lugar no calcanhar ou na traseira de um terço do pé; (II) mediopé, na qual o calcanhar e os metatarsos contatam o solo praticamente ao mesmo tempo (geralmente ao longo da margem lateral); e (III) do antepé, em que o contato inicial é feito na metade anterior do pé, após o qual o contato do calcanhar, normalmente, acontece logo em seguida (63). Uma variabilidade significativa na DPP durante o correr pode ser observada entre os corredores que pisam com o antepé, mediopé e o retropé (13).

A proporção de corredores que utilizam diferentes padrões de pisada foi investigada entre corredores de elite e sub-elite. Hasegawa et al. (63), encontraram a proporção de retropé, mediopé, e antepé de 74,9\%,23,7\% e $1,4 \%$, respectivamente. Num estudo realizado por Larson et al. (64) os padrões pisada entre corredores recreacionais e sub-elite foram de 94,4\% (retropé), 3,6\% (mediopé) e 1,9\% (antepé). Os resultados por Hasegawa et al. (63) e Larson et al. (64) indicam que a maior parte dos corredores utilizam uma pisada retropé. 
No entanto, parece haver uma diferença na distribuição dos retropé, mediopé, e antepé entre a elite e o grupo de corredores sub-elite/recreational, com maiores distribuições de classificados como retropé entre os corredores menos experientes (65).

Estudos compararam as propriedades cinéticas e cinemática, bem como a eficiência metabólica relativa destes vários padrões de pisada durante o correr. Tem sido sugerido que as pisadas antepé e mediopé podem proteger os pés e membros inferiores de alguns dos danos experimentados por uma elevada percentagem de corredores, enquanto que a pisada retropé durante o correr tem sido sugerida como um preditor importante para o desenvolvimento de lesões relacionadas ao correr. Outros autores discordam, sugerindo que o tipo de pisada influencia o tipo e a natureza da lesão $(36,62,66-70)$.

De acordo com Willems et al. (71) as características da pisada e da pressão plantar em indivíduos estão relacionadas a lesões. Alterações nos padrões biomecânicos do correr, como na distribuição de pressão plantar, podem conduzir a lesões e a identificação dessas alterações pode ajudar na prevenção dessas lesões.

A pressão é geralmente focada inicialmente na borda lateral do calcanhar. Ela se move muito rapidamente para o aspecto medial do calcanhar e para o antepé, onde dois picos da pressão de magnitude quase iguais sobre as cabeças dos primeiro e segundo metatarsos são vistos. Esse tipo de análise de mapeamento é alterado significativamente pelo uso de calçados, podendo claramente mudar a aplicação de pressão para diferentes estruturas anatômicas do pé $(13,57)$.

Contudo, não foram encontrados estudos que avaliassem a distribuição de pressão plantar no correr de crianças de diferentes faixas etárias, tampouco estudos que descrevam de que forma são alteradas as cargas distribuídas ao longo do pé na medida em que essa habilidade locomotora se desenvolve. 


\subsubsection{Pressão Plantar na Marcha de Crianças}

O crescimento corporal com o padrão normal não é linear, isto é, o crescimento da cabeça, tronco e membros inferiores ocorre de forma diferente, $o$ que influencia as proporções do corpo. Ao nascer, a contribuição relativa da cabeça e do tronco de estatura total é maior e diminui ao longo da infância até a adolescência. Assim, a criança é caracterizada por uma cabeça e tronco proporcionalmente maiores, e as pernas mais curtas em comparação com um adulto. As estruturas ósseas e musculares também estão sujeitas a processos surpreendentes de desenvolvimento na infância. Os primeiros movimentos coordenados causam tensões de compressão e de tração, que são importantes para a mudança apropriada da forma dos ossos e músculos para os requisitos de carga futuros. O pé também cresce e se desenvolve a fim de cumprir os requisitos para a locomoção $(2,6,72)$.

Não é possível então supor que uma criança se locomova de forma idêntica a um adulto. Dessa forma, muitos pesquisadores tem se ocupado em analisar a DPP durante o andar em crianças.

O aumento da estatura leva a uma diminuição da área de contato do mediopé, o que indica um menor achatamento do arco longitudinal. O que resulta em um aumento e mudança de parâmetros de carga de acordo com as outras regiões do pé. $\mathrm{O}$ aumento da massa do corpo, no entanto, causa o aumento das cargas no mediopé e uma redução para a maior parte das outras regiões do pé (6).

Bosch et al. (73) em uma pesquisa longitudinal realizada com crianças de 01 até seus 10 anos de idade encontraram que há um aumento gradual dos valores de pico de pressão e de comprimento do pé que não está terminado aos 10 anos de idades e indica o desenvolvimento contínuo do crescimento do pé. O mesmo grupo de pesquisadores comparou o caminhar de crianças com uma 
amostra de adultos de 32 anos de idade, as crianças investigadas alcançaram entre 53\% e $99 \%$ das pressões regionais. Esta é uma indicação do desenvolvimento avançado, mas ainda incompleto do pico de pressão plantar na idade de 10 anos.

O correr, por sua vez, impõe maiores cargas mecânicas ao sistema musculoesquelético do que o andar, gerando maiores demandas do sistema locomotor e deixando-o mais suscetível à lesões. Informações a respeito de como essas cargas afetam as forças que devem ser sustentadas pelo pé são importantes na avaliação do desenvolvimento motor e para o desenvolvimento de produtos, como os tênis esportivos infantis $(8,13)$.

\subsubsection{Velocidade e Distribuição de Pressão Plantar}

É comum observar uma variação na velocidade da marcha patológica em crianças (74). Há dados disponíveis para a avaliação e comparação da velocidade durante o caminhar em crianças e este estudo pretende contribuir oferecendo um conjunto de dados durante o correr em crianças.

A velocidade tende a aumentar com a idade durante o caminhar de crianças. Contudo, esse aumento não é identificado quando os dados de velocidade são normalizados pelo comprimento de membros inferiores e pela aceleração da gravidade. É possível que as diferenças observadas na velocidade absoluta da marcha entre idades aconteçam devido às diferenças de tamanho entre os sujeitos (75).

A velocidade da corrida influencia os ângulos articulares, a força de reação do solo, os momentos articulares bem como as forças de impacto e a distribuição de pressão plantar (13). Ho et al. (55) e Kernozek e Zimmer (76) informaram que a força máxima e a pressão aumentaram em todas as regiões do pé com o ritmo crescente do correr em adultos. 
Ho et al. (55) também observaram aumento na inversão do pé durante a fase de apoio (aumento do pico de pressão no lado lateral do pé) quando se corre mais rápido, entre as jovens mulheres não treinadas testadas, 1,5, 2,0 e 2,5 m/s em uma esteira com inclinação de $0 \%$.

A velocidade influencia a área de contato, a força máxima, o tempo de contato e a carga relativa da superfície plantar do correr tanto de adulto como de adolescentes $(13,55,61)$. Avaliando adolescentes altamente treinados, Fourchet et al. (61) compararam a distribuição de pressão plantar durante o trote e corrida e encontraram que em todo o pé, a área de contato (-1,2\%), a força máxima ($12,3 \%)$ e o pico de pressão $(-15,1 \%)$ foram menores no trote que na corrida e apenas o tempo de contato foi maior $(+20,1 \%)$. Além disso, descreveram um aumento na carga relativa na porção medial $(+6,7 \%)$ e central $(+3,7 \%)$ da região da frente do pé e de uma redução da carga relativa nos dedos menores $(-8,4 \%)$ durante o trote. 


\section{MATERIAL E MÉTODOS}

Trata-se de um estudo de caráter descritivo longitudinal, pois consiste na análise e descrição de características de determinados sujeitos antes e após o período de um ano e sua relação com determinados fenômenos.

\subsection{Sujeitos}

O estudo foi conduzido com 28 crianças com idade entre 4 e 6 anos, de ambos os sexos, participantes de escolas da Regional de Ensino do Recanto das Emas da Secretaria de Educação do Distrito Federal. Os participantes foram divididos em 3 grupos de acordo com a idade, G4 $(n=10)$ composto por 4 meninas e 6 meninos com média de 4,70 $\pm 0,19$ anos de idade na avaliação 1, G5 $(n=10)$ composto por 4 meninas e 6 meninos com média de 5,64 $\pm 0,17$ anos de idade na avaliação 1 e $\mathrm{G} 6(\mathrm{n}=8)$ composto por 4 meninas e 4 meninos com média de 6,69 $\pm 0,31$ anos de idade na avaliação 1 . A avaliação 1 (A1) foi realizada na primeira semana de setembro de 2013 e a avaliação 2 (A2) na primeira semana de setembro de 2014.

As escolas participantes foram selecionadas por conveniência e seus responsáveis (direção da escola) aceitaram participar da pesquisa. Uma carta convite foi enviada aos pais ou responsáveis explicando os procedimentos e objetivos da pesquisa (Apêndice I). Para os indivíduos que aceitaram participar do estudo foram agendados dias e horários para a coleta, que foi realizada em um dia na própria escola onde a criança estudava, durante o período de aula. Os responsáveis pelos avaliados receberam informações a respeito da pesquisa e assinaram a autorização e o Termo de Consentimento Livre e Esclarecido (Apêndice II), assim como responderam o questionário entregue pelo pesquisador sobre dados pessoais e histórico de doenças e lesões (Apêndice III). 


\subsection{Critérios de Inclusão}

- Ser um indivíduo eutrófico;

- Estar dentro de uma das faixas etárias estipuladas.

\subsection{Critérios de Exclusão}

- Não preencher corretamente os documentos entregues pelo pesquisador;

- Apresentar histórico de qualquer doença ou lesão que possa afetar a locomoção.

O projeto foi aprovado pelo Comitê de Ética em Pesquisa com Seres Humanos da Faculdade de Ciências da Saúde da Universidade de Brasília (UnB) com parecer de número 788.162 (Anexo I).

\subsection{Procedimentos}

Antes da avaliação 1 os responsáveis pelas instituições de ensino foram procurados para esclarecimentos sobre a pesquisa e permissão para realização da pesquisa no ambiente escolar. Após obter a autorização, um convite foi enviado aos responsáveis pelas crianças com esclarecimentos sobre a pesquisa, anexados ao convite estavam a ficha de avaliação e o Termo de Consentimento Livre e Esclarecido aos responsáveis das crianças. Os documentos enviados aos responsáveis e preenchidos foram recolhidos nas escolas. Após análise da documentação foram agendadas as coletas. A coleta de dados foi realizada na escola, durante o período letivo. Para cada crianças foi realizada a avaliação antropométrica e a avaliação baropodométrica. 
Após um ano do momento da primeira coleta de dados, foi realizada a avaliação 2. Um novo contato foi estabelecido com as escolas bem como com os responsáveis e avaliados e uma nova data de coleta de dados foi agendada para cada criança. Os procedimentos de coletas de dados na avaliação 2 foram os mesmos conduzidos na avaliação 1 .

\subsubsection{Seleção dos avaliados}

Duas escolas da Secretaria de Educação do Distrito Federal que atendem alunos de 4 a 7 anos de idade foram visitadas e o documento com esclarecimentos sobre a pesquisa foi enviado a residência de todas as crianças que se enquadraram nas faixas etárias estipuladas, assim como a Autorização de participação na pesquisa e o Termo de Consentimento Livre e Esclarecido. As crianças que trouxeram a documentação devidamente assinada pelo responsável, que atenderam aos critérios de inclusão e não apresentaram doenças ou lesão que pudessem afetar a locomoção se tornaram aptos a participarem da pesquisa.

Para as crianças selecionadas foi agendado um dia para coleta de dados. A criança foi recrutada na sala de aula e direcionada de forma individual a um espaço reservado da escola. A criança recebeu explicações simplificadas sobre a pesquisa, bem como instruções em relação a liberdade para negar a participar da pesquisa em qualquer momento, por qualquer motivo e sem nenhum prejuízo. $\mathrm{O}$ mesmo procedimento se repetiu na segunda avaliação.

\subsubsection{Avaliação Antropométrica}

Foram medidos os dados antropométricos de cada criança, incluindo massa e estatura corporal, para a caracterização dos sujeitos avaliados. A massa corporal, em quilogramas $(\mathrm{kg})$, foi registrada utilizando-se uma balança digital científica, com precisão de $0,01 \mathrm{~kg}$. A estatura corporal, em centímetros $(\mathrm{cm})$, 
foi avaliada através de estadiômetro móvel compacto do tipo trena, com precisão de $0,1 \mathrm{~cm}$.

\subsubsection{Avaliação Baropodométrica}

Os sujeitos foram submetidos à avaliação baropodométrica utilizando o Sistema Emed-AT (Novel, Alemanha) conectado via USB a um notebook. O sistema é composto de um dispositivo de medição denominado plataforma pedográfica Emed n-50® (Novel, Alemanha), o software Emed/R (próprio do sistema Emed-AT) e um computador portátil para aquisição de dados, armazenamento e recuperação para análise. A plataforma possui dimensões de 690x403x18 mm e 6.080 sensores capacitivos e resolução de 4 sensores $/ \mathrm{cm}^{2}$. A frequência de amostragem da plataforma Emed n-50 ® é de $50 \mathrm{~Hz}$. Após a aquisição dos dados, o software permite a divisão do pé em regiões e produz um relatório com os valores de DPP para o pé total e por região (Anexo II).
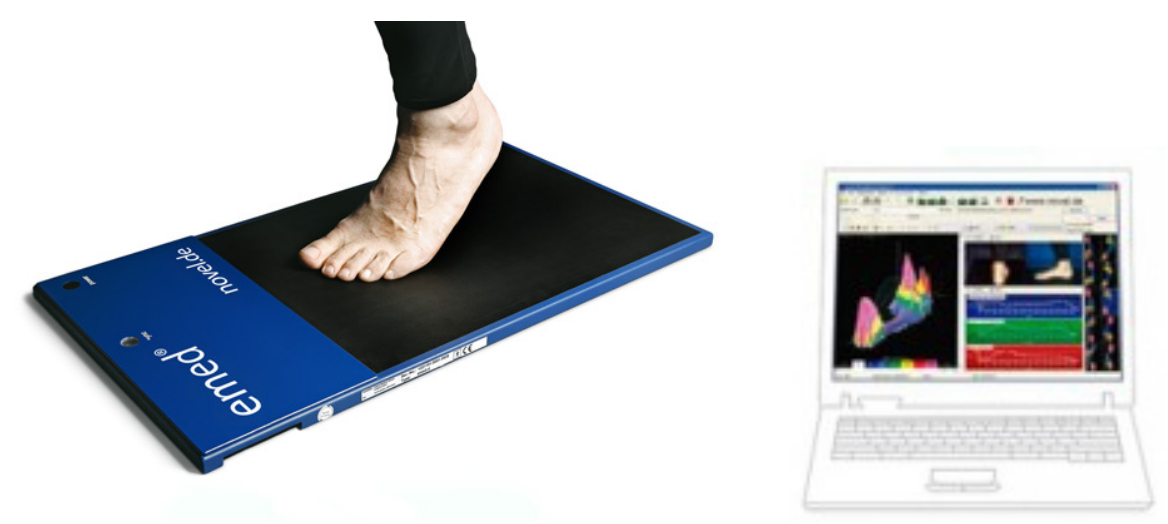

Figura 4 - Plataforma de avaliação da DPP Emed® e representação do software utilizado pelo sistema Emed-AT (Novel, Alemanha) (77).

Durante a avaliação cada indivíduo correu descalço em linha reta, sobre uma passarela de Etinil Vinil Acetato (EVA), com 3,66 metros de comprimento. 
No centro da passarela foi posicionada a plataforma baropodométrica para não haver diferença entre a altura da plataforma e o solo. Foi adicionado espaço de cerca de 2 a 3 metros nas duas extremidades da plataforma de EVA para aceleração e desaceleração e o espaço foi sinalizado por cones, como mostra a Figura 5.

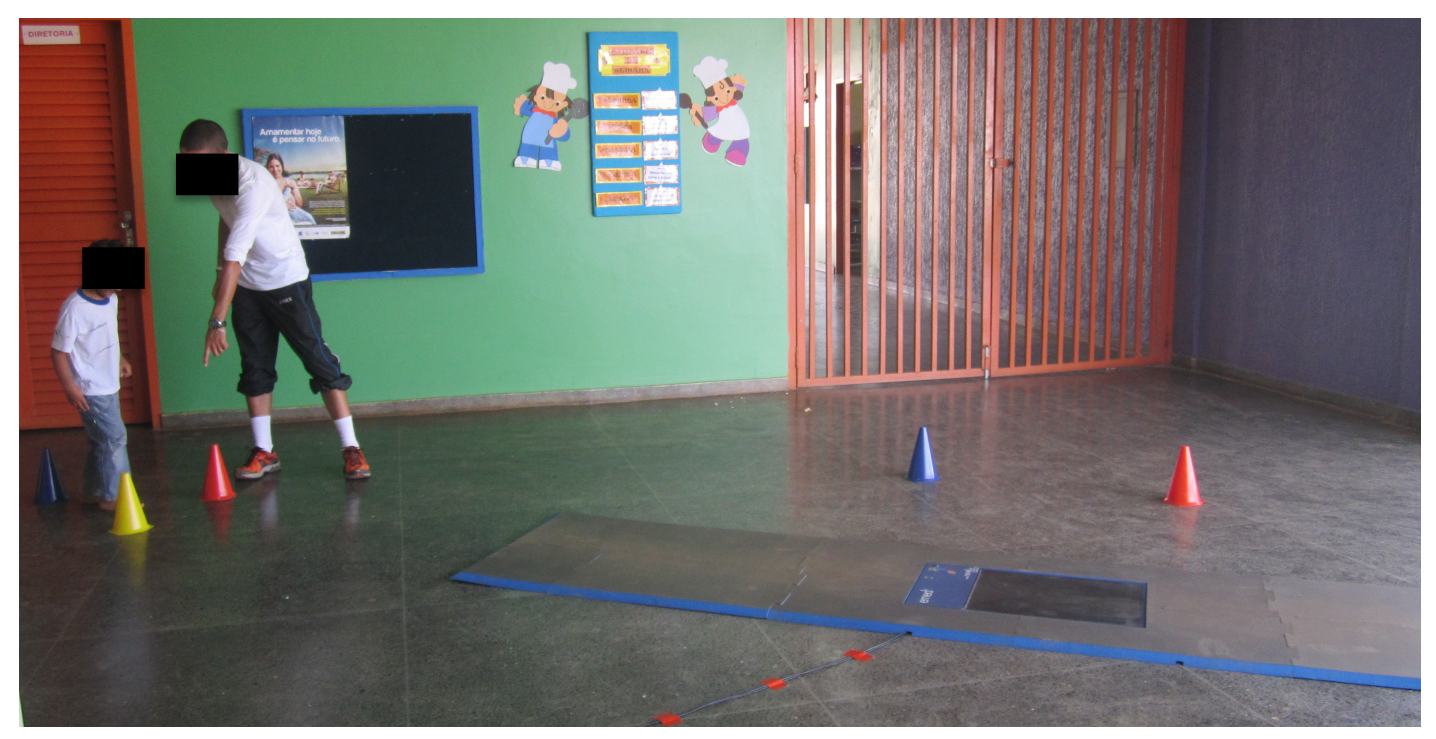

Figura 5 - Passarela de EVA com plataforma e posicionamento dos avaliados.

Foram registradas cinco passadas válidas com o pé direito e cinco passadas válidas com o pé esquerdo sobre a plataforma para aumentar a fidedignidade das medidas de pressão plantar, e analisadas as médias dos valores encontrados nas cinco tentativas. $\mathrm{O}$ indivíduo foi orientado a correr olhando para uma marca posicionada na parede na altura da cabeça, sem se preocupar em pisar na área da plataforma e os pesquisadores foram responsáveis por ajustar o posicionamento do indivíduo para que a passada fosse válida e realizada com o membro desejado. Foi considerada passada válida, quando o indivíduo pisou com toda a planta do pé dentro da plataforma, sem a intenção de acertá-la. 
Os sujeitos correram com velocidade auto-selecionada e ordem do membro escolhida de forma aleatória, com intervalo de 30 segundos entre as tentativas. Algumas crianças apresentaram dificuldade em manter o padrão de velocidade e de tamanho da passada durante as tentativas, dificultando o posicionamento durante as tentativas, sendo assim, as abordagens válidas a plataforma fora da ordem determinada por sorteio não foram descartadas. A velocidade de cada tentativa foi registrada por dois avaliadores através do uso de cronômetros, acionados no inicio e fim da passarela de EVA. Cada avaliado realizou adaptação pré-tentativa para familiarização e ajustes acerca do posicionamento no percurso para correta abordagem a plataforma.

O correr com tênis tem a pressão plantar significativamente reduzida quando comparada com o correr descalço (53) e o tipo de calçado também pode influenciar os dados de pressão plantar (57). Sendo assim, os sujeitos foram avaliados descalços.

As variáveis dependentes deste estudo foram: (1) área de contato (AC) área total de contato do pé com o solo em $\mathrm{cm}^{2},(2)$ pico de pressão plantar (PP) máxima pressão registrada nas áreas plantares específicas em $\mathrm{kPa}$, (3) força máxima relativa (Fmáx\%) - somatório da força mensurada em cada sensor da plataforma normalizado pelo peso corporal e (4) tempo de contato (TC\%) - em porcentagem do tempo de apoio no solo.

Essas variáveis foram analisadas em 05 regiões plantares distintas: retropé, mediopé, antepé, hálux e dedos, e no pé total ou não dividido, totalizando 24 variáveis dependentes. As máscaras que dividem o pé são calculadas automaticamente pelo software, sendo o retropé toda a região compreendida entre $0 \%$ e $30 \%$ da área de contato total do pé, $0 \%$ correspondendo a extremidade do calcanhar e 100\% ao último dedo do pé, o mediopé toda a região entre $30 \%$ e $60 \%$, o antepé toda a região entre $60 \%$ e $80 \%$, o hálux e os dedos correspondem a região entre $80 \%$ e $100 \%$ da área de 
contato do pé, sendo a região do hálux considerado a porção de $0 \%$ a $33 \%$ dessa região, iniciando a contagem na parte medial do pé e a região dos dedos a porção entre $33 \%$ e $100 \%$ da largura dessa região, como demostra a Figura 6.

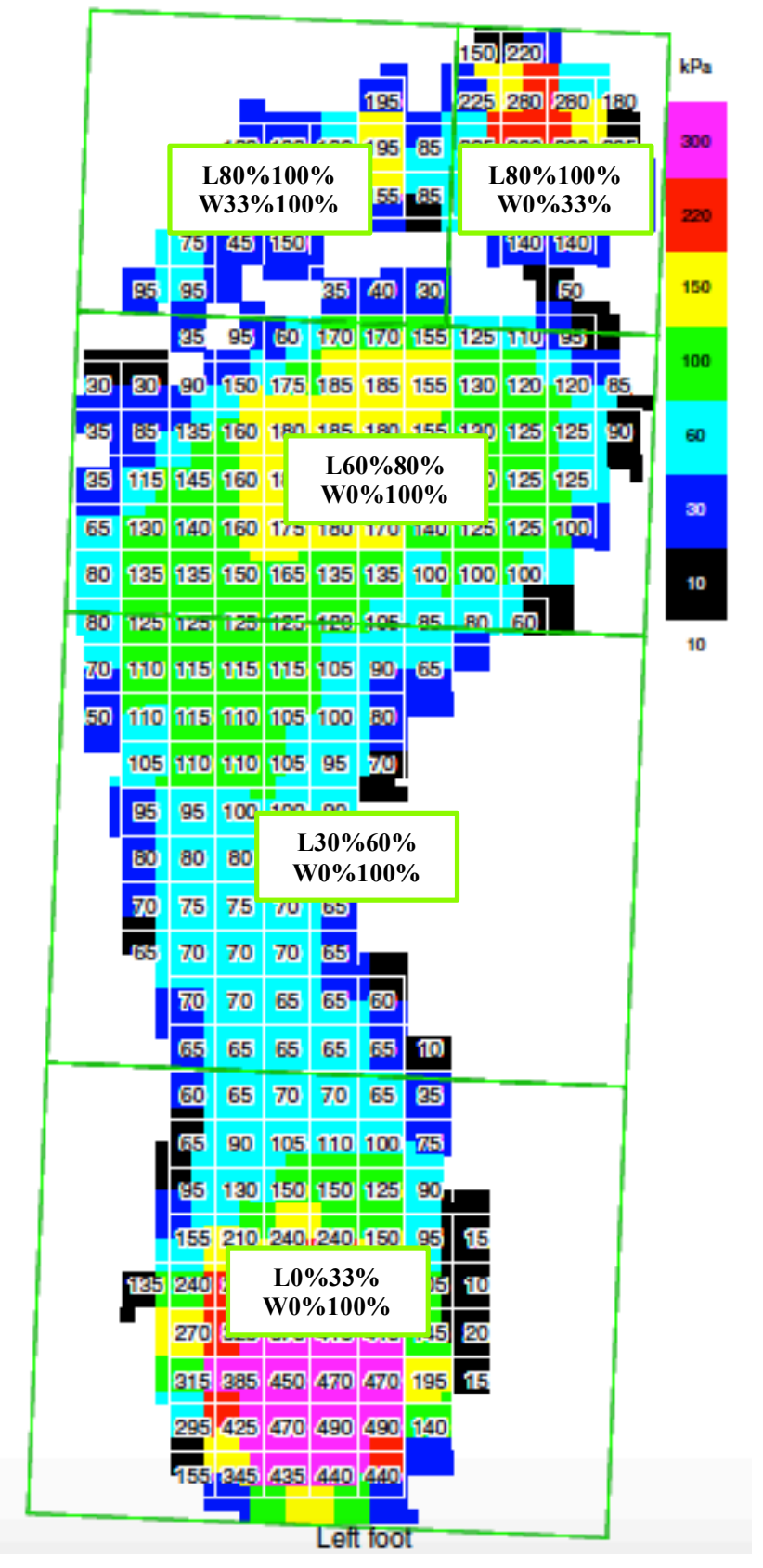

Figura 6 - Imagem gerada pelo software Emed/R (Novel, Alemanha) com a representação da divisão do pé em 5 regiões. L - corresponde a foot length, ou comprimento do pé; $\mathrm{W}$ corresponde a foot width, ou largura do pé. 


\subsection{Procedimentos Estatísticos}

Para análise estatística dos dados utilizou-se o programa Statistical Package for the Social Science (SPSS) versão 20.0 para Mac OS X.

Foram realizadas análise descritiva, com dados de tendência central e dispersão, para limpeza do banco de dados e verificados os pressupostos básicos de normalidade multivariada, por meio do teste de hipóteses de Shapiro-Wilk da normalidade univariada para cada variável dependente, e homogeneidade das matrizes de covariância, através do teste de Levene e do teste de Box.

O Teste-t para amostras pareadas foi utilizado para comparar as médias das 04 variáveis dependentes de cada região do pé e para o pé total, assim como para a massa, estatura, velocidade entre a avaliação 1 e a avaliação 2 e para comparar os valores encontrados para os dois pé.

A análise de variância multivariada MANOVA com traço de Pillai foi utilizada, tendo os grupos (G4, G5 e G6) como fatores para comparar as médias das 04 variáveis dependentes de cada região do pé e para o pé total, a velocidade e as características antropométricas entre os grupos de diferentes faixas etárias. O Post hoc de Bonferroni foi utilizado para identificar as diferenças entre os grupos etários. O nível de significância adotado foi de $\mathrm{p}<0,05$.

\subsection{Limitações}

Apesar da importância da velocidade como um dos principais fatores que influenciam as variáveis de distribuição de pressão plantar, o estudo registrou mas não controlou a velocidade de execução do correr. Dessa forma, a comparação entre os valores de DPP para as diferentes situações de interesse da pesquisa pode ser influenciada pela velocidade em que a corrida foi executada.

Algumas crianças apresentaram dificuldade em realizar tentativas válidas, realizando um número maior de tentativas para aquisição completa dos dados. $\mathrm{O}$ 
mesmo tipo de dificuldade foi relatada em outro estudo avaliando o caminhar para mesma faixa etária (39). Como consequência, a motivação pode ter sido afetada durante os testes.

O questionário, contendo as informações sobre histórico de lesões e doenças que afetam o sistema locomotor, foi aplicado somente na avaliação 1 . Sendo assim, a evolução do histórico relatado pelos responsáveis não pode ser controlada. 


\section{RESULTADOS}

Não foram encontradas diferenças estatisticamente significativas entre as variáveis de DPP e a velocidade de execução da corrida para o pé direito e esquerdo, com exceção da variável força máxima relativa para o G4 na região do antepé $(\mathrm{p}=0,011)$ e da variável tempo de contato no hálux $(\mathrm{p}=0,044)$ e da variável área de contato para o G5 na região do retropé $(p=0,047)$. Portanto, neste estudo serão apresentados apenas os dados para o pé esquerdo.

\subsection{Comparação da Pressão Plantar entre Avaliações 1 e 2}

A Tabela 1 apresenta a comparação dos valores médios de massa, estatura, índice de massa corporal (IMC) e velocidades entre a avaliação 1 e a avaliação 2 para cada um dos grupos.

Tabela 1 - Comparação entre a avaliação 1 e a avaliação 2 para as variáveis massa, estatura e velocidade.

\begin{tabular}{|c|c|c|c|c|c|c|}
\hline & \multirow[b]{2}{*}{$\mathrm{n}$} & & Massa (kg) & Estatura (cm) & IMC & Velocidade $(\mathrm{m} / \mathrm{s})$ \\
\hline & & & Média \pm DP & Média \pm DP & Média \pm DP & Média \pm DP \\
\hline \multirow{3}{*}{ G4 } & \multirow{3}{*}{10} & $\mathrm{~A} 1$ & $19,05 \pm 2,68$ & $109,19 \pm 3,63$ & $15,93 \pm 0,52$ & $2,93 \pm 0,32$ \\
\hline & & A2 & $22,28 \pm 3,50$ & $116,46 \pm 3,59$ & $16,36 \pm 0,61$ & $2,38 \pm 0,17$ \\
\hline & & $\mathrm{p}$ & 0,000 & 0,000 & & 0,000 \\
\hline \multirow{3}{*}{ G5 } & \multirow{3}{*}{10} & A1 & $18,95 \pm 2,55$ & $112,78 \pm 4,20$ & $14,86 \pm 0,46$ & $3,06 \pm 0,41$ \\
\hline & & A2 & $21,32 \pm 3,04$ & $118,92 \pm 4,71$ & $15,04 \pm 0,55$ & $2,27 \pm 0,32$ \\
\hline & & $\mathrm{p}$ & 0,000 & 0,000 & & 0,000 \\
\hline \multirow{3}{*}{ G6 } & \multirow{3}{*}{8} & A1 & $24,47 \pm 5,83$ & $121,43 \pm 4,90$ & $16,44 \pm 1,04$ & $3,58 \pm 0,36$ \\
\hline & & $\mathrm{A} 2$ & $27,98 \pm 7,85$ & $127,21 \pm 5,55$ & $17,08 \pm 1,31$ & $2,41 \pm 0,37$ \\
\hline & & $\mathrm{p}$ & 0,016 & 0,000 & & 0,000 \\
\hline
\end{tabular}

Nível de significância de $\mathrm{p}<0,05$.

É possível observar que a massa e a estatura corporal aumentaram significativamente e a velocidade diminuiu significativamente para todos os 
grupos durante o período de um ano. A diminuição da velocidade foi de cerca de $19 \%$ para o G4, 26\% para o G5 e 33\% para o G6. Não houve diferença significativa para o IMC entre as avaliações 1 e 2.

A Tabela 2 apresenta a comparação dos valores médios de comprimento do pé e DPP entre a avaliação 1 e a avaliação 2 para cada um dos grupos.

O comprimento do pé aumentou para todos os grupos avaliados no período de um ano, mas o aumento foi significativo apenas para os G4 e G5. No G4 o pé teve aumento médio de $0,94 \mathrm{~cm}$ o que corresponde a um acréscimo de $5 \%$ a média de comprimento do pé na avaliação 1 , no G5 o aumento foi de 1,43 cm (+8\%) e no G6 de $0,78 \mathrm{~cm}(+4 \%)$.

O valor médio do índice de arco plantar dinâmico, medido durante o correr, pode classificar todos os grupos como pé plano, tanto na avaliação 1 quanto na avaliação 2 (78).

O G4 aumentou significativamente a área de contato considerando o pé total e nas regiões do retropé, antepé e hálux. No G5, todas as variáveis de DPP aumentaram significativamente considerando o pé total e a região do retropé. A área de contato também aumentou no antepé. Houve ainda uma tendência de diminuição dos valores médios encontrados nas regiões do hálux e dos dedos para o G5, contudo essa diminuição é significativa somente para a força máxima relativa na região dos dedos. O G6 aumentou significativamente a força máxima relativa e a área de contato no pé total enquanto a área de contato aumentou na região do antepé e do hálux.

A área de contato no pé total aumentou cerca de $8 \%$ para os grupos no período de um ano. No retropé o aumento da área de contato foi de $16 \%$ para o G5, no antepé o aumento foi de 9\% para o G4 e G6 e 12\% para o G5. 
Tabela 2 - Comparação entre a avaliação 1 e a avaliação 2 para as variáveis de pressão plantar.

\begin{tabular}{|c|c|c|c|c|c|c|c|c|c|c|}
\hline & & \multicolumn{2}{|c|}{$\mathrm{G} 4(\mathrm{n}=10)$} & & \multicolumn{2}{|c|}{ G5 $(n=10)$} & \multicolumn{4}{|c|}{ G6 $(n=8)$} \\
\hline & & A1 & A2 & & A1 & A2 & & A1 & A2 & \\
\hline & & $\begin{array}{l}\text { Média } \\
\pm \mathrm{DP}\end{array}$ & $\begin{array}{l}\text { Média } \\
\pm \mathrm{DP}\end{array}$ & $\mathrm{p}$ & $\begin{array}{l}\text { Média } \\
\pm \mathrm{DP}\end{array}$ & $\begin{array}{l}\text { Média } \pm \\
\text { DP }\end{array}$ & $\mathrm{p}$ & $\begin{array}{c}\text { Média } \pm \\
\text { DP }\end{array}$ & $\begin{array}{l}\text { Média } \pm \\
\text { DP }\end{array}$ & $\mathrm{p}$ \\
\hline \multirow{2}{*}{\multicolumn{2}{|c|}{$\begin{array}{l}\text { Comprimento do } \\
\text { pé }(\mathrm{cm})\end{array}$}} & 17,95 & 18,89 & & 18,04 & 19,47 & \multirow{2}{*}{, 000} & 19,28 & 20,06 & \\
\hline & & $\pm 0,74$ & $\pm 1,05$ &, 041 & $\pm 0,66$ & $\pm 0,83$ & & $\pm 1,30$ & $\pm 1,37$ & \\
\hline \multirow{2}{*}{\multicolumn{2}{|c|}{$\begin{array}{c}\text { Índice do Arco } \\
\text { Plantar }\end{array}$}} & 0,326 & 0,309 & & 0,327 & 0,310 & \multirow{2}{*}{, 016} & 0,276 & 0,271 & \\
\hline & & $\pm 0,030$ & $\pm 0,025$ & & $\pm 0,033$ & $\pm 0,029$ & & $\pm 0,043$ & $\pm 0,051$ & \\
\hline \multirow{6}{*}{ Total } & \multirow{2}{*}{$\mathrm{PP}_{(\mathrm{kPa})}$} & 434,00 & 378,61 & & 447,10 & 545,90 & \multirow{2}{*}{,023 } & 461,88 & 513,50 & \multirow{4}{*}{, 047} \\
\hline & & $\pm 149,22$ & $\pm 62,82$ & & $\pm 160,40$ & $\pm 211,23$ & & $\pm 102,78$ & $\pm 221,91$ & \\
\hline & \multirow[b]{2}{*}{ Fmáx\% } & 223,50 & 229,16 & & 221,40 & 245,51 & \multirow[b]{2}{*}{, 008} & 230,13 & 244,57 & \\
\hline & & $\pm 20,38$ & $\pm 25,24$ & & $\pm 21,52$ & $\pm 24,59$ & & $\pm 16,37$ & $\pm 10,80$ & \\
\hline & & 77,08 & 83,45 & & 74,84 & 81,46 & \multirow[b]{2}{*}{, 000} & 81,87 & 87,19 & \multirow{2}{*}{,019 } \\
\hline & $\mathrm{AC}\left(\mathrm{cm}^{2}\right)$ & $\pm 9,89$ & $\pm 8,47$ & ,033 & $\pm 10,84$ & $\pm 11,06$ & & $\pm 12,58$ & $\pm 14,85$ & \\
\hline \multirow{8}{*}{ Retropé } & \multirow{2}{*}{$\mathrm{TC} \%$} & 43,28 & 44,92 & & 42,70 & 49,60 & & 45,07 & 40,22 & \\
\hline & & $\pm 9,77$ & $\pm 9,37$ & & $\pm 9,46$ & $\pm 10,16$ & ,015 & $\pm 9,98$ & $\pm 10,92$ & \\
\hline & & 383,38 & 317,93 & & 356,30 & 453,80 & & 367,44 & 297,88 & \\
\hline & $\mathrm{PP}_{(\mathrm{kPa})}$ & $\pm 149,62$ & $\pm 79,46$ & & $\pm 173,40$ & $\pm 166,28$ &, 020 & $\pm 91,66$ & $\pm 141,44$ & \\
\hline & & 138,66 & 113,46 & & 108,72 & 138,23 & & 122,10 & 99,21 & \\
\hline & Fmax\% & $\pm 31,97$ & $\pm 23,77$ & & $\pm 27,75$ & $\pm 35,46$ & ,044 & $\pm 26,42$ & $\pm 38,40$ & \\
\hline & & 19,03 & 20,76 & & 18,23 & 21,22 & & 21,27 & 21,55 & \\
\hline & $\mathrm{AC}\left(\mathrm{cm}^{2}\right)$ & $\pm 2,39$ & $\pm 2,00$ & ,019 & $\pm 2,45$ & $\pm 3,38$ &, 000 & $\pm 4,07$ & $\pm 5,75$ & \\
\hline & & 58,99 & 59,96 & & 61,25 & 61,04 & & 58,95 & 61,52 & \\
\hline & $10 \%$ & $\pm 6,18$ & $\pm 3,36$ & & $\pm 4,88$ & $\pm 6,26$ & & $\pm 5,11$ & $\pm 4,75$ & \\
\hline & & 120,60 & 124,78 & & 121,80 & 133,30 & & 124,50 & 138,81 & \\
\hline Medioné & $\mathrm{PP}_{(\mathrm{kPa})}$ & $\pm 33,92$ & $\pm 37,73$ & & $\pm 32,20$ & $\pm 40,89$ & & $\pm 30,91$ & $\pm 37,96$ & \\
\hline IVIediope & & 63,34 & 55,15 & & 62,99 & 63,44 & & 42,89 & 39,73 & \\
\hline & Fmax\% & $\pm 17,18$ & $\pm 15,62$ & & $\pm 15,43$ & $\pm 10,37$ & & $\pm 7,56$ & $\pm 10,96$ & \\
\hline & & 20,86 & 21,03 & & 20,37 & 21,19 & & 18,77 & 19,55 & \\
\hline & $\mathrm{AC}\left(\mathrm{cm}^{2}\right)$ & $\pm 3,99$ & $\pm 3,25$ & & $\pm 5,13$ & $\pm 4,76$ & & $\pm 5,07$ & $\pm 5,87$ & \\
\hline & & 81,36 & 82,93 & & 83,10 & 82,39 & & 85,79 & 85,96 & \\
\hline & $1 C \%$ & $\pm 6,04$ & $\pm 5,27$ & & $\pm 4,45$ & $\pm 4,92$ & & $\pm 6,96$ & $\pm 4,19$ & \\
\hline & & 210,00 & 223,34 & & 215,30 & 240,30 & & 306,63 & 332,25 & \\
\hline & $\mathrm{PP}_{(\mathrm{kPa})}$ & $\pm 52,15$ & $\pm 56,40$ & & $\pm 30,70$ & $\pm 40,02$ & & $\pm 60,21$ & $\pm 82,48$ & \\
\hline Antepe & & 118,38 & 127,53 & & 125,99 & 132,58 & & 151,50 & 159,11 & \\
\hline & rma & $\pm 13,74$ & $\pm 16,56$ & & $\pm 8,10$ & $\pm 14,08$ & & $\pm 22,58$ & $\pm 28,80$ & \\
\hline & & 23,74 & 26,02 & & 22,80 & 25,54 & & 27,43 & 30,08 & \\
\hline & $\mathrm{AC}\left(\mathrm{cm}^{2}\right)$ & $\pm 2,37$ & $\pm 2,72$ &, 000 & $\pm 2,46$ & $\pm 3,11$ &, 000 & $\pm 2,67$ & $\pm 3,70$ & ,032 \\
\hline & TCo & 77,55 & 80,13 & & 80,77 & 77,84 & & 82,30 & 83,93 & \\
\hline & $10 \%$ & $\pm 2,80$ & $\pm 3,83$ & & $\pm 4,41$ & $\pm 7,63$ & & $\pm 4,04$ & $\pm 2,90$ & \\
\hline & & 306,90 & 293,67 & & 324,20 & 308,20 & & 287,75 & 441,63 & \\
\hline HáluY & $\mathrm{PP}$ & $\pm 125,99$ & $\pm 116,39$ & & $\pm 106,01$ & $\pm 118,47$ & & $\pm 73,62$ & $\pm 256,41$ & \\
\hline Halux & & 42,11 & 35,87 & & 44,06 & 39,15 & & 39,81 & 41,22 & \\
\hline & Fmax\% & $\pm 13,11$ & $\pm 8,89$ & & $\pm 12,06$ & $\pm 18,85$ & & $\pm 9,09$ & $\pm 8,57$ & \\
\hline & & 6,76 & 7,33 & & 6,83 & 7,17 & & 8,15 & 8,56 & \\
\hline & $\mathrm{AC}\left(\mathrm{cm}^{2}\right)$ & $\pm 0,72$ & $\pm 1,11$ & ,024 & $\pm 0,74$ & $\pm 0,90$ & & $\pm 0,80$ & $\pm 0,80$ & ,032 \\
\hline & & 82,19 & 82,11 & & 80,14 & 78,34 & & 82,54 & 84,59 & \\
\hline & $1 C \%$ & $\pm 6,09$ & $\pm 1,84$ & & $\pm 6,99$ & $\pm 5,43$ & & $\pm 2,06$ & $\pm 3,22$ & \\
\hline & & 160,60 & 180,59 & & 150,60 & 135,40 & & 183,50 & 178,75 & \\
\hline & $\mathrm{P}$ & $\pm 32,12$ & $\pm 52,52$ & & $\pm 31,10$ & $\pm 27,28$ & & $\pm 75,38$ & $\pm 27,75$ & \\
\hline Dedos & & 26,32 & 20,67 & & 18,77 & 13,25 & & 19,00 & 17,91 & \\
\hline & $\mathrm{Fmax \%}$ & $\pm 9,23$ & $\pm 2,76$ & & $\pm 3,84$ & $\pm 3,94$ & ,008 & $\pm 8,70$ & $\pm 6,62$ & \\
\hline & & 8,11 & 8,31 & & 6,65 & 6,39 & & 8,11 & 8,55 & \\
\hline & $\mathrm{AC}\left(\mathrm{cm}^{2}\right)$ & $\pm 1,17$ & $\pm 1,02$ & & $\pm 1,54$ & $\pm 1,13$ & & $\pm 2,03$ & $\pm 1,75$ & \\
\hline
\end{tabular}

Nível de significância de $\mathrm{p}<0,05$. 
Quando considerado o pico de pressão no pé total o aumento foi de cerca de $12 \%$ para G4 e G6 e $22 \%$ para o G5. No retropé o pico de pressão diminuiu cerca de $18 \%$ para G4 e G6 e aumentou cerca de $27 \%$ para o G5. Na região do hálux houve aumento de cerca de 53\% para o G6 na região dos dedos aumento de cerca de $12 \%$ para o G4 e diminuição de $10 \%$ para o G5.

A força máxima no pé total aumentou de cerca de $221 \%$ para $246 \%$ do peso corporal para o G5 e de cerca $230 \%$ para $245 \%$ do peso corporal para o G6. O mesmo efeito é visto no retropé para o G5 $(+30 \%)$ e no antepé para os três grupos $(+8 \%)$. No retropé houve a diminuição do força máxima relativa para os G4 (-25\%) e G6 (-23\%).

O tempo de contato do retropé em relação ao tempo de contato do pé no solo para o G5 aumentou de cerca de $43 \%$ na avaliação 1 para cerca de $50 \%$ na avaliação 2 .

\subsection{Comparação entre os Grupos}

Não houve efeito significativo do fator idade na maioria das variáveis de DPP.

Houve, porém, uma tendência de aumento de comprimento do pé com o aumento da idade, a diferença média entre os grupos nas avaliações foi de 0,63 $\mathrm{cm}$. Comparando os três grupos a diferença foi significativa apenas na avaliação 1 , entre o G4 e o G6 $(\mathrm{p}=0,046)$.

A Figura 7 demonstra os valores médios de pico de pressão em cada região do pé e no pé total encontrados na avaliação 1 para cada grupo. 


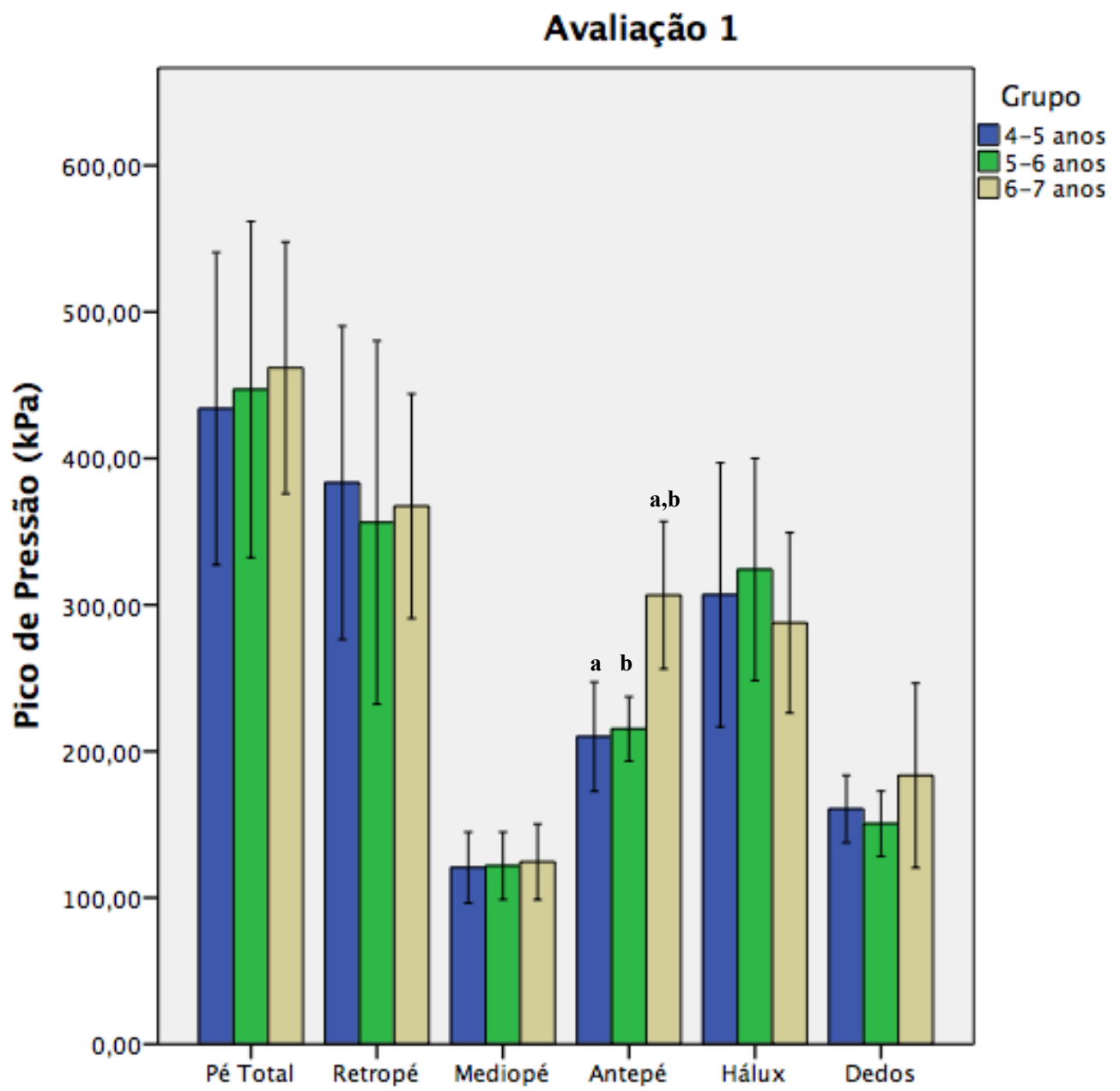

Figura 7 - Comparação entre os grupos etários para pico de pressão na avaliação 1 considerando o pé total e as diferentes regiões do pé. a - Diferença significativa entre os grupos G4 e G6; b - Diferença significativa entre os grupos G5 e G6. Nível de significância de $\mathrm{p}<0,05$.

Na avaliação 1, o G6 é diferente significativamente na região do antepé do G4 $(\mathrm{p}=0,001)$ e do G5 $(\mathrm{p}=0,002)$.

A Figura 8 demonstra os valores médios de pico de pressão em cada região do pé e no pé total encontrados na avaliação 2 para cada grupo. 


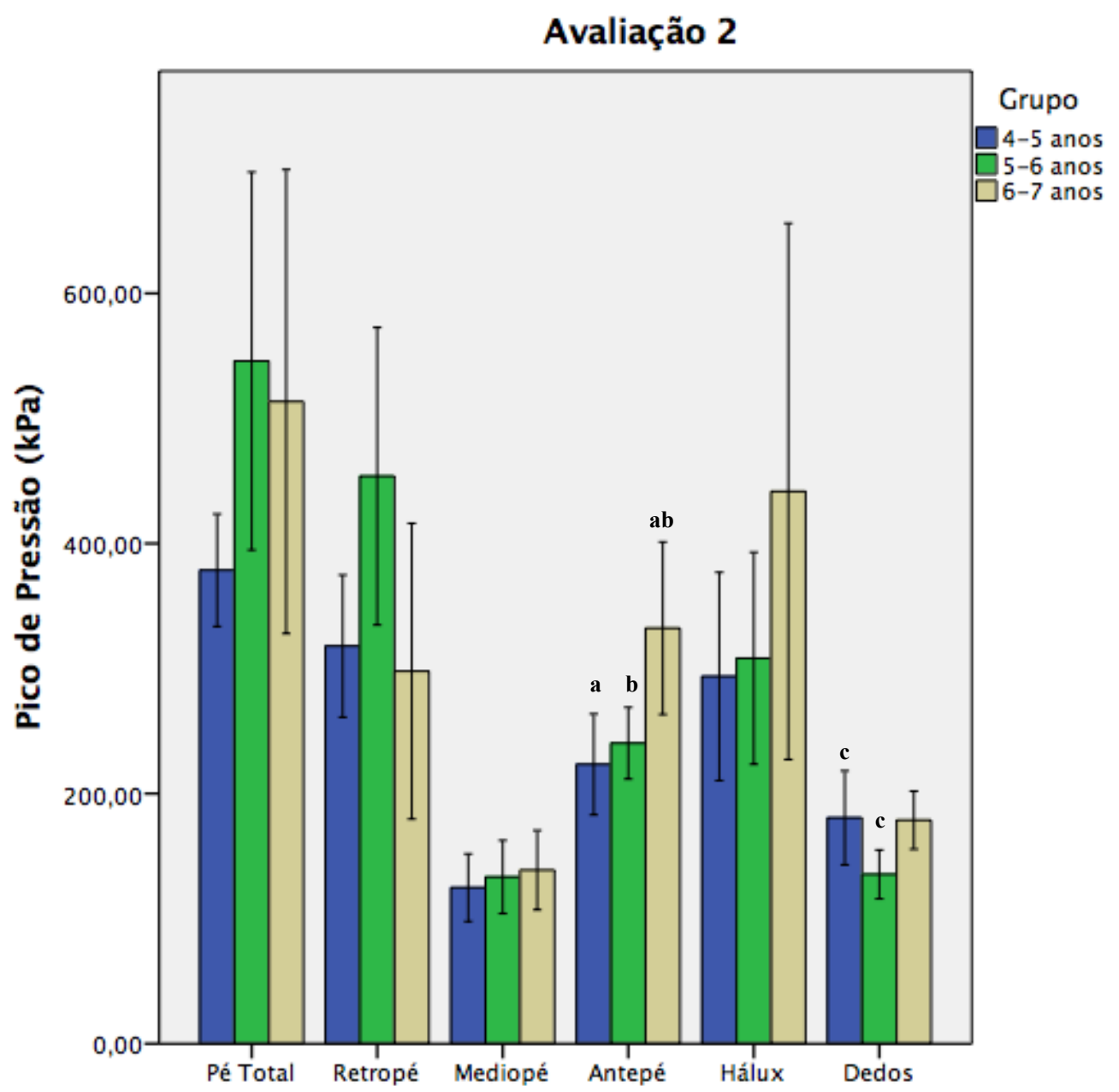

Figura 8 - Comparação entre os grupos etários para pico de pressão na avaliação 2 considerando o pé total e as diferentes regiões do pé. a - Diferença significativa entre os grupos G4 e G6; b - Diferença significativa entre os grupos G5 e G6; c - Diferença significativa entre os grupos G4 e G5. Nível de significância de $\mathrm{p}<0,05$.

$\mathrm{Na}$ avaliação 2, o G6 também é diferente significativamente na região do antepé do $\mathrm{G} 4(\mathrm{p}=0,002)$ e do $\mathrm{G} 5$ na região $(\mathrm{p}=0,011)$ e o $\mathrm{G} 4$ é diferente significativamente do G5 anos na região dos dedos $(p=0,043)$.

Os valores médios de força máxima relativa no pé total e em cada região encontrados na avaliação 1 para cada grupo estão representados na Figura 9. 


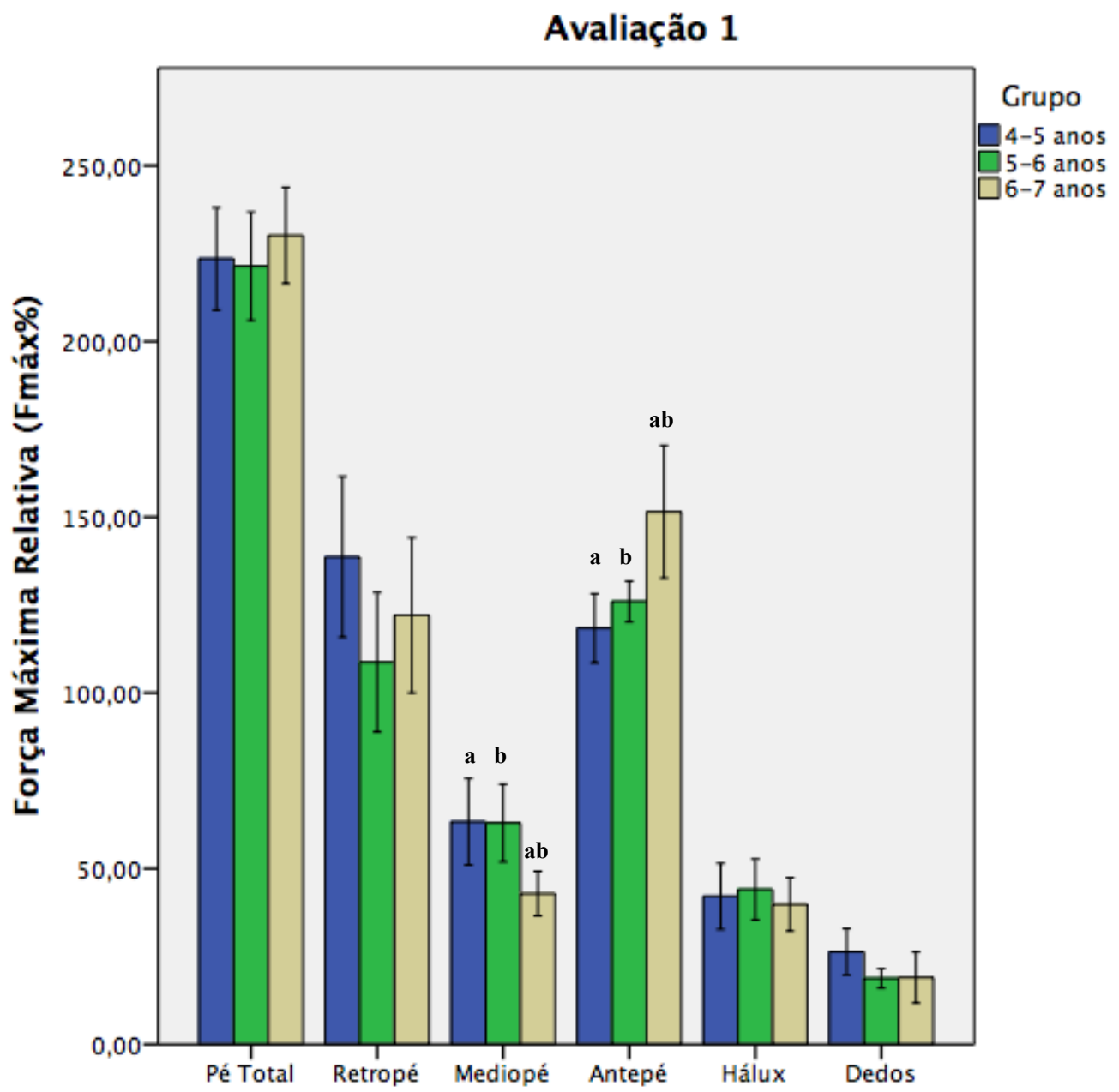

Figura 9 - Comparação entre os grupos etários para força máxima relativa na avaliação 1 considerando o pé total e as diferentes regiões do pé. a - Diferença significativa entre os grupos G4 e G6; b - Diferença significativa entre os grupos G5 e G6. Nível de significância de $\mathrm{p}<0,05$.

O grupo G6 é diferente significativamente nas regiões do mediopé e antepé do G4 ( $\mathrm{p}=0,019$ e 0,000) e do G5 $(\mathrm{p}=0,021$ e 0,005) na avaliação 1 .

Os valores médios de força máxima relativa no pé total e em cada região encontrados na avaliação 2 para cada grupo estão representados na Figura 10. 


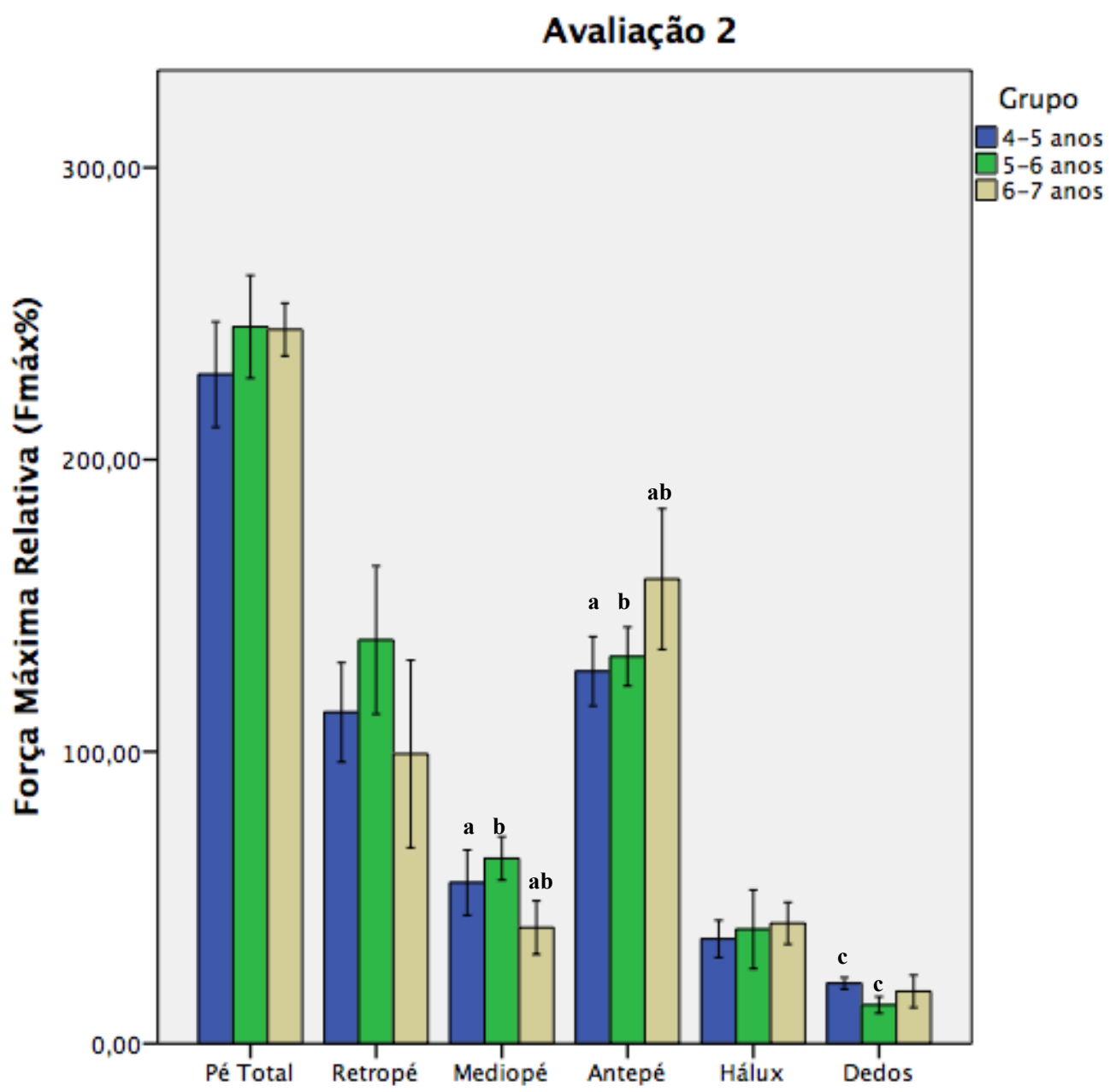

Figura 10 - Comparação entre os grupos etários para força máxima relativa na avaliação 2 considerando o pé total e as diferentes regiões do pé. a - Diferença significativa entre os grupos G4 e G6; b - Diferença significativa entre os grupos G5 e G6; c - Diferença significativa entre os grupos G4 e G5. Nível de significância de $p<0,05$.

$\mathrm{Na}$ avaliação 2, o G6 é diferente significativamente do G4 na região do antepé $(\mathrm{p}=0,008)$ e do G5 nas regiões do mediopé $(\mathrm{p}=0,002)$ e antepé $(\mathrm{p}=$ 0,030). O G4 é diferente significativamente do G5 na região dos Dedos ( $\mathrm{p}=$ $0,004)$.

A Figura 11 apresenta os valores médios de tempo de contato relativo em cada região do pé e no pé total na avaliação 1 para cada grupo. 


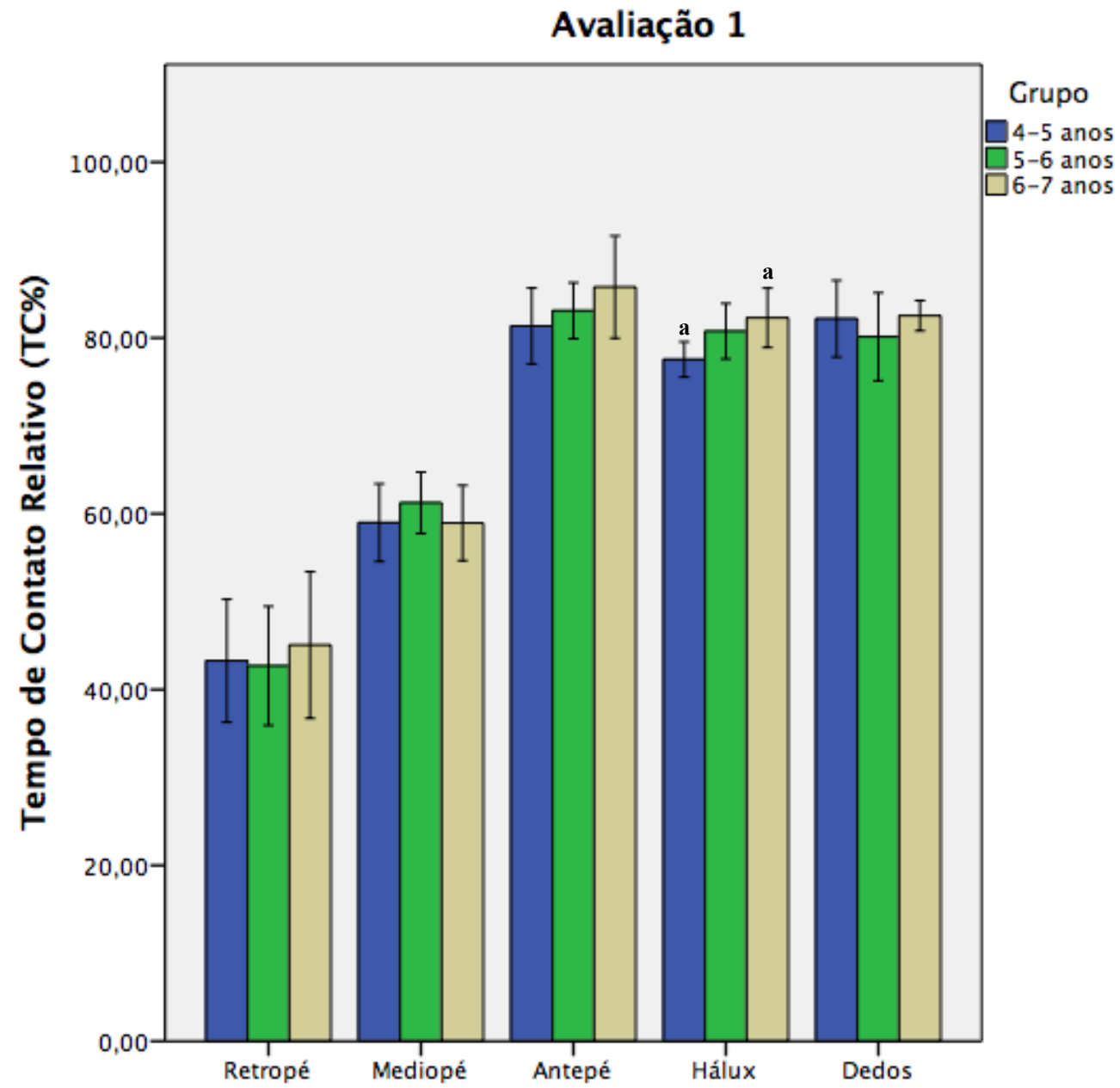

Figura 11 - Comparação entre os grupos etários para tempo de contato relativo na avaliação 1 considerando o pé total e as diferentes regiões do pé. a - Diferença significativa entre os grupos G4 e G6. Nível de significância de $\mathrm{p}<0,05$.

A Figura 12 apresenta os valores médios de tempo de contato relativo em cada região do pé e no pé total na avaliação 2 para cada grupo. 


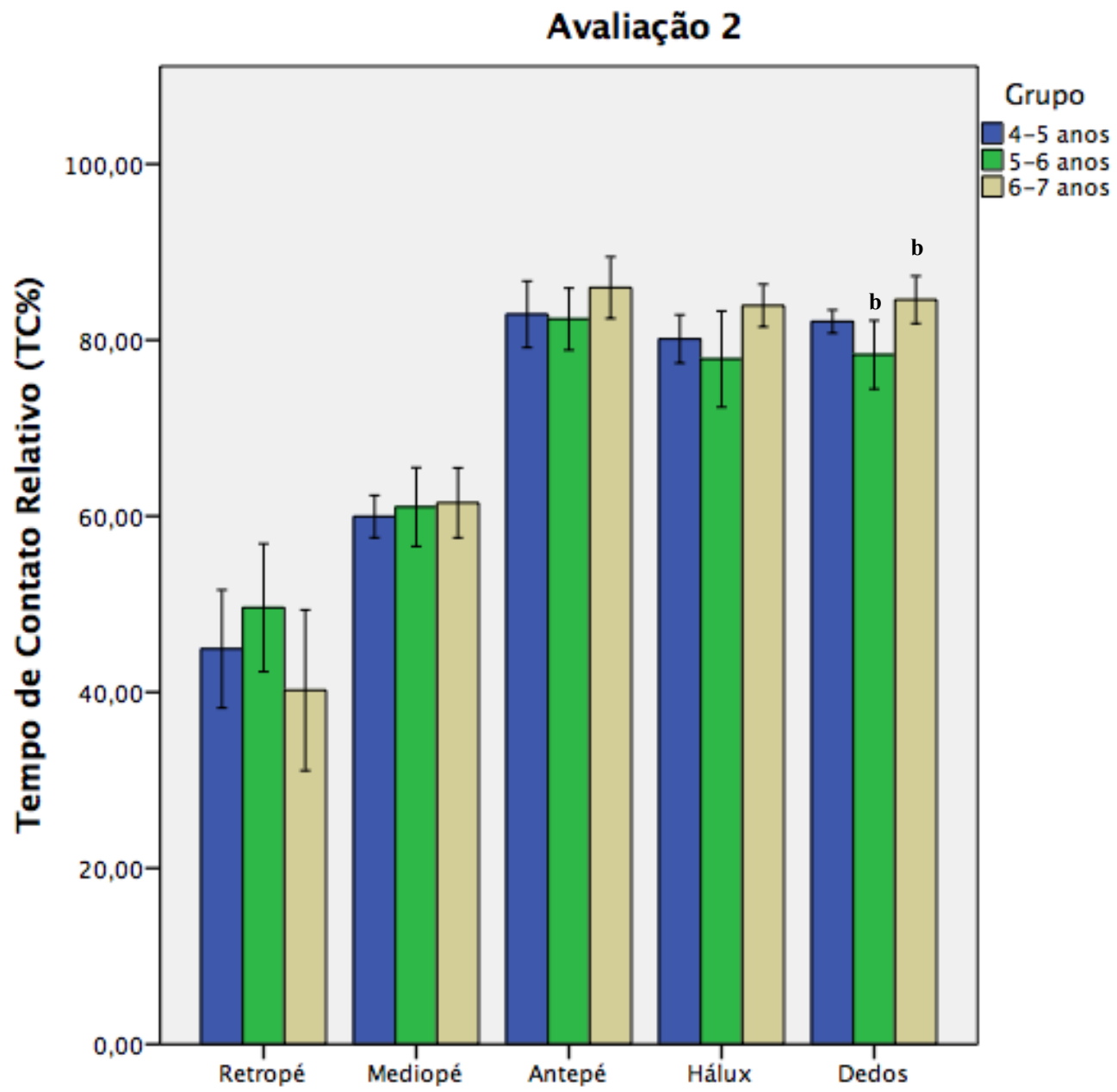

Figura 12 - Comparação entre os grupos etários para tempo de contato relativo na avaliação 2 considerando o pé total e as diferentes regiões do pé. b - Diferença significativa entre os grupos G5 e G6. Nível de significância de $\mathrm{p}<0,05$.

Há diferença significativa para o tempo de contato relativo entre o G6 e o G4 na região do hálux $(\mathrm{p}=0,043)$ na avaliação 1 e entre o G6 e o G5 na região dos dedos $(\mathrm{p}=0,006)$ na avaliação 2 .

A área de contato em cada região do pé e no pé total na avaliação 1 está representada na Figura 13. 


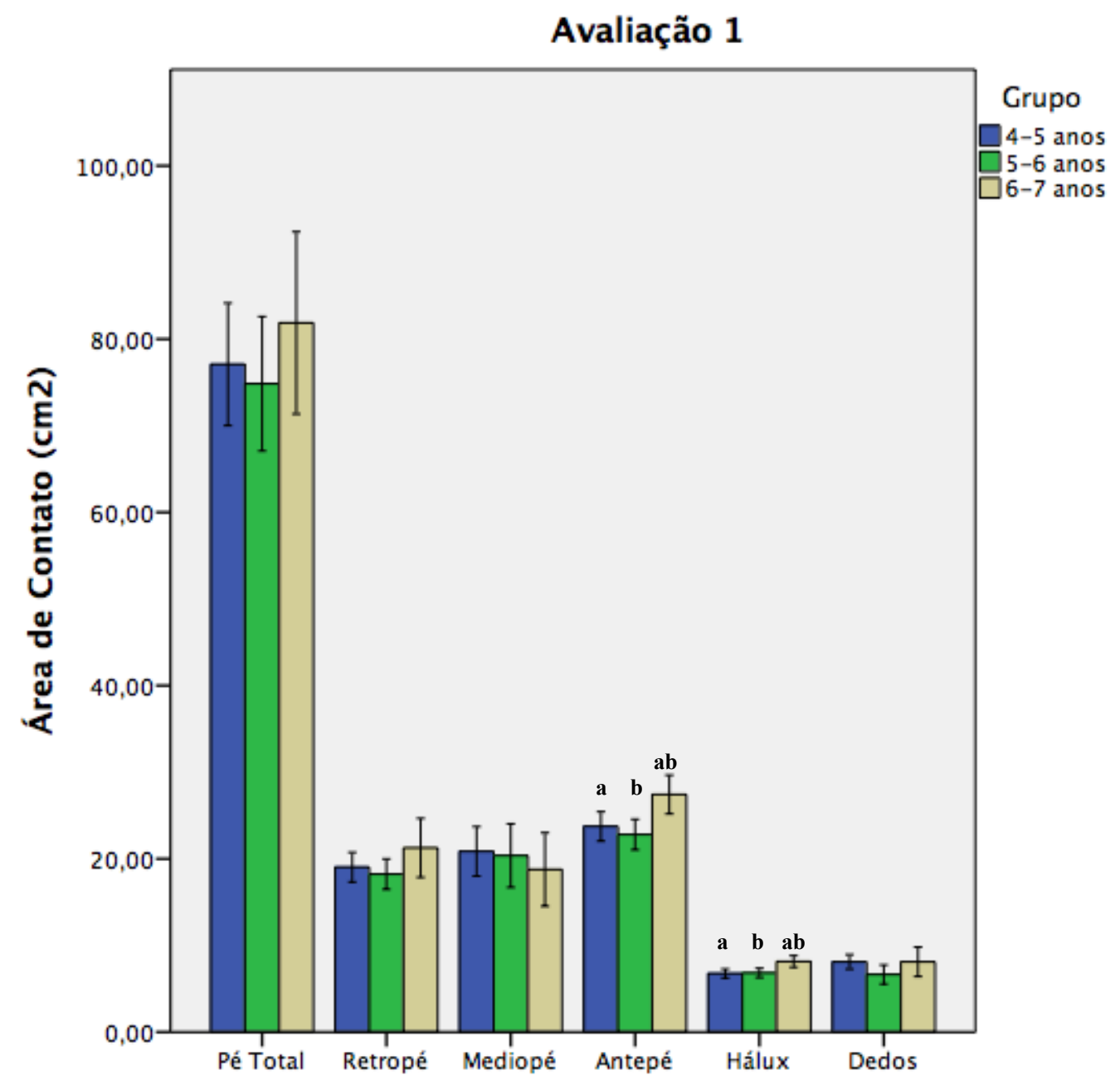

Figura 13 - Comparação entre os grupos etários para área de contato na avaliação 1 considerando o pé total e as diferentes regiões do pé. a - Diferença significativa entre os grupos G4 e G6; b - Diferença significativa entre os grupos G5 e G6. Nível de significância de $\mathrm{p}<0,05$.

Na avaliação 1, o G6 é diferente significativamente nas regiões do antepé e hálux do G4 ( $\mathrm{p}=0,036$ e $\mathrm{p}=0,037)$ e do G5 ( $\mathrm{p}=0,002$ e $\mathrm{p}=0,003)$.

A área de contato em cada região do pé e no pé total na avaliação 2 está representada na Figura 14. 


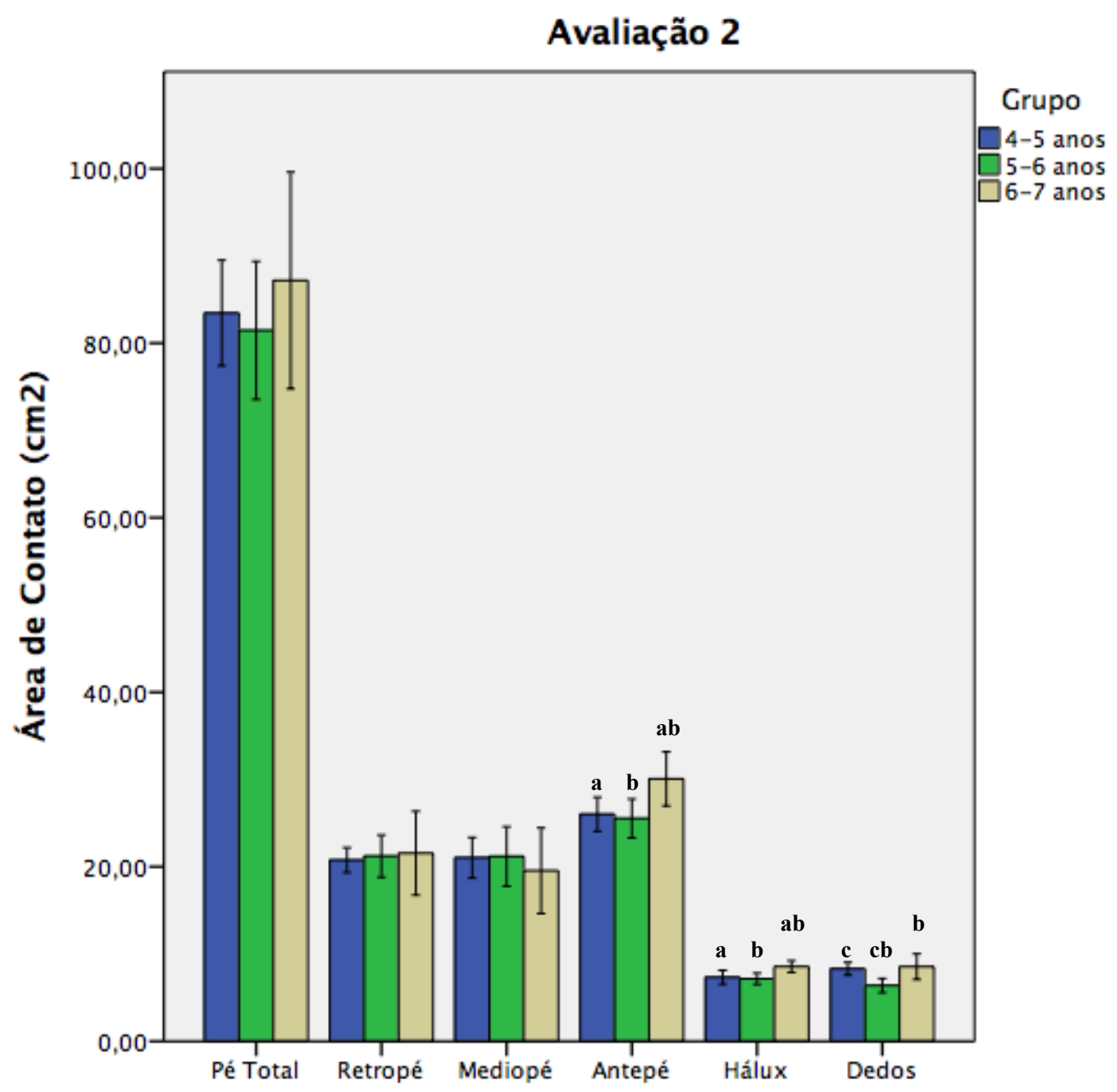

Figura 14 - Comparação entre os grupos etários para área de contato na avaliação 2 considerando o pé total e as diferentes regiões do pé. a - Diferença significativa entre os grupos G4 e G6; b - Diferença significativa entre os grupos G5 e G6; c - Diferença significativa entre os grupos G4 e G5. Nível de significância de $\mathrm{p}<0,05$.

Na avaliação 2, o G6 é diferente significativamente do G4 nas regiões do antepé $(\mathrm{p}=0,036)$ e hálux $(\mathrm{p}=0,037)$ e também do $\mathrm{G} 5$ nas regiões do antepé ( $\mathrm{p}$ $=0,017)$, hálux $(\mathrm{p}=0,015)$ e dedos $(\mathrm{p}=0,005)$. O G4 é diferente significativamente do G5 na região dos dedos $(p=0,009)$ na avaliação 2.

Pode-se observar que as principais diferenças ocorreram entre o G6 e os demais grupos. Para as variáveis massa, estatura e velocidade, os valores médios foram maiores para o G6 em comparação com os G4 e G5 na avaliação 1 e na 
avaliação 2. Para as variáveis de DPP, a tendência foi de valores médios significativamente maiores para os avaliados do G6 tanto na avaliação 1 como na avaliação 2 . 


\section{DISCUSSÃO}

\subsection{Distribuição de Pressão Plantar no Período de um Ano}

Analisando os valores de DPP entre a avaliação 1 e a avaliação 2 pode-se observar que o comprimento do pé aumentou para todos os grupos avaliados. No G4 o pé aumentou 5\%, no G5 o aumento foi de $8 \%$ e no G6 de 4\%. Um estudo longitudinal que testou crianças por 9 anos durante o caminhar relatou o aumento contínuo do comprimento do pé do primeiro aos 10 anos de idade em crianças saudáveis (6).

A área de contato também aumentou, no pé total o aumento foi de cerca de $8 \%$ para os três grupos, no retropé para os grupos G4 (9\%) e G5 (16\%), no antepé para os três grupos (cerca de 9\% para o G4 e G6 e 12\% para o G5), no hálux de 8\% para o G4 e 5\% para o G6. A área de contato não aumentou na região do mediopé e dos dedos para os três grupos etários.

No estudo de Bosch et al. (6) a área de contato no mediopé mostrou uma diminuição de $12 \%$, enquanto que a área de contato do retropé, antepé e hálux aumentou no período de observação.

As estruturas ósseas e musculares estão sujeitas a grandes processos de desenvolvimento na infância. A coordenação dos movimentos gera tensões de compressão e de tração, que preparam as estruturas ósseas, musculares e neurológicas para cumprir os requisitos de carga. O pé está entre as estruturas que sofrem adaptações associadas ao crescimento e desenvolvimento $(2,6,72)$. A área de contato em cada região do pé está relacionada ao tamanho do pé da criança, que cresce e se desenvolve acompanhando o crescimento e oferecendo os requisitos para locomoção (3). Assim, espera-se que a área de contato também aumente no período de um ano. 
Não foram encontrados dados de DPP plantar durante o correr para comparação, mas o aumento da estatura está associada a uma diminuição na área de contato do mediopé durante o caminhar em crianças, enquanto o aumento da massa corporal tem uma significante influencia sobre o aumento das cargas no mediopé e a redução para a maior parte das outras regiões (6). Considerando que maiores cargas mecânicas são impostas ao sistema musculoesquelético durante o correr quando comparadas as impostas durante o andar $(1,8,13)$, é possível que o aumento da estatura, arco plantar e massa corporal expliquem o comportamento da área de contato no mediopé durante o correr. Enquanto a área no mediopé diminui durante o caminhar para esta faixa etária, as forças atuantes durante o correr apresentam magnitudes maiores em consequência da velocidade mantendo baixa a depressão do arco longitudinal e, consequentemente, os valores de área de contato no mediopé.

Houve aumento dos valores médios para as variáveis tempo de contato relativo $(+7 \%)$, pico de pressão $(+27 \%)$ e força máxima relativa $(+30 \%)$ entre a avaliação 1 e a avaliação 2 na região do retropé para o G5. Houve ainda uma tendência à diminuição dos valores médios encontrados na região do hálux e dos dedos para esse mesmo grupo. Para o G4 e G6 houve diminuição dos valores médios de pico de pressão $(-17 \%$ e $-19 \%)$ e de força máxima relativa $(-25 \%$ e $23 \%$ ) na região do retropé.

Fourchet et al. (61) encontraram área de contato, força máxima e pico de pressão menores no trote do que na corrida ao avaliar o correr em adolescentes. Sabe-se que com o aumento da velocidade de corrida, o contato inicial do pé com o solo tende a passar do calcanhar, no trote ou corrida em baixa velocidade, para a ponta do pé, no sprint ou corrida de alta velocidade $(1,13,28)$. O tipo de pisada tem sido relatado como um fator importante que altera a forma como os valores de DPP ocorrem e uma grande variabilidade na DPP durante o correr pode ser observada entre corredores que abordam o solo com o antepé, mediopé 
e retropé $(25,53)$. A velocidade dos três grupos etários diminuiu significativamente na segunda avaliação em relação à primeira, mas a média da velocidade do G5 é a menor registrada na segunda avaliação. É possível que a baixa velocidade durante o correr esteja afetando o padrão de movimento e, assim, gerando valores de DPP maiores no retropé e menores no hálux e nos dedos para o G5 e valores menores de pico de pressão e força máxima relativa para os grupos G4 e G6.

O pico de pressão no pé total aumentou cerca de $12 \%$ para o G4 e G6 e $22 \%$ para o G5, aumentou também cerca de $10 \%$ no antepé para os três grupos, $53 \%$ na região do hálux para o G6 e na 12\% região dos dedos para o G4.

No estudo de Bosch et al. (6) os valores de pico de pressão aumentaram gradualmente no pé total e aumentos contínuos dos valores de pico de pressão regionais também foram observadas. O aumento gradual dos valores de pico de pressão não está terminado aos 10 anos e indica o desenvolvimento contínuo do crescimento do pé (3). Em comparação com uma amostra de adultos de 32 anos de idade, crianças alcançaram entre 53\% e $99 \%$ dos picos de pressão regionais (73). Esta é uma indicação para o desenvolvimento avançado, mas ainda incompleto de pressões de pico na idade de 10.

Contudo Fourchet et al. (61) encontraram menores valores de pico de pressão plantar $(-15,1 \%)$ e força máxima $(-12,3 \%)$ no trote em relação ao correr em adolescentes corredores. Outros estudos com adultos também detectaram o aumento do pico de pressão com o ritmo crescente do correr $(55,76)$. Apesar de o presente estudo comparar as avaliações e não a velocidade, houve uma diminuição da velocidade na avaliação 2 em relação a avaliação 1 e os valores de pico de pressão se comportaram de forma distinta nas crianças avaliadas do que nos adolescentes corredores ou adultos. O processo de crescimento e desenvolvimento está atuando como fator importante para que haja essa 
diferença, mas a técnica de corrida executada pelos adolescentes treinados ou pelos adultos provavelmente difere da executada pelas crianças.

A força máxima no pé total aumentou para o G5 e G6, o mesmo é visto no retropé para o G5 (+30\%) e no antepé para os grupos G4, G5 e G6.

Estudo anterior apontou aumento da força máxima relativa sob o pé total, retropé, antepé, hálux e dedos e diminuição apenas na região do mediopé (6).

\subsection{Distribuição de Pressão Plantar entre os Grupos Etários}

Para as variáveis de DPP a tendência foi de valores médios significativamente maiores para os avaliados do G6 em relação aos outros grupos tanto na avaliação 1 como na avaliação 2 . Há aumento dos valores médios de pico de pressão na região do antepé e da área de contato nas regiões do antepé, hálux e dedos para o G6 em relação aos demais grupos. Este aumento está provavelmente relacionado aos maiores valores médios de velocidade e a maior habilidade técnica no movimento do correr. Isso significa que o contato inicial pode estar sendo deslocado para a região anterior do pé.

De acordo com alguns estudos, a maturidade da DPP durante o andar parece ser obtida entre 5 e 6 anos de idade $(3,21,37,39,73)$. A área de contato e os valores da força máxima revelam apenas pequenas diferenças após os 4,5 anos de idade quando comparados com os valores dos adultos (73). Samson et al. (79) avaliaram os parâmetros da articulação do tornozelo e as forças de reação do solo durante o caminhar e encontraram um padrão adulto aos 5 anos de idade. Os dados encontrados no presente estudo sugerem que a maturidade do padrão de DPP durante o correr está ainda em desenvolvimento nesta faixa etária.

A estatura parece ter influência significativa no comprimento do pé e na largura do pé. A cada $5 \mathrm{~cm}$ de diferença na estatura corporal foi relatado 
aumento de $0,4 \mathrm{~cm}$ no comprimento do pé e a diminuição de $0,3 \mathrm{~cm}$ na largura do pé. O crescimento em estatura também influencia o aumento da força máxima no retropé, antepé e hálux, da área de contato no calcanhar e no hálux, do pico de pressão no pé total, retropé, antepé e hálux, influencia também a diminuição do pico de pressão, força máxima e área de contato no mediopé. $\mathrm{O}$ aumento da massa corporal influenciou a largura do pé, a cada $1 \mathrm{~kg}$ de aumento de massa corporal foi relatado aumento de $0,08 \mathrm{~cm}$ na largura do pé. A massa corporal também influenciou a diminuição da força máxima no retropé, antepé, hálux e dedos e o aumento do pico de pressão, força máxima e área de contato no mediopé (6).

O pé humano proporciona ao corpo uma base estável, capaz de conferir de forma eficiente suporte, flexibilidade e equilíbrio para o rolamento do pé e deslocamento de peso durante a marcha, sendo uma estrutura biomecânica de complexa (41-43). Seu crescimento e desenvolvimento para atender as exigências da locomoção logo nos primeiros anos de vida é igualmente complexo. De acordo com alguns estudos, a distribuição de pressão plantar madura durante o andar é obtida entre os 5 e 6 anos de idade $(3,21,37,39)$. Os dados do presente estudo parecem ser o resultado da combinação do crescimento corporal e desenvolvimento das estruturas do pé entre os 4 e 6 anos de idades, com o aumento da habilidade de realizar a tarefa motora da corrida. Mas faltam estudos que analisem todos esses fatores e seus efeitos na distribuição das cargas plantares durante o correr em diferentes velocidades.

O G6 apresentou valores menores de força máxima relativa em relação aos demais grupos na região do mediopé e maiores na região do antepé na avaliação 1 e na avaliação 2. O que reforça a hipótese de que o contato com o solo está sendo realizado de forma diferente para o G6. Segundo Samson et al. (79) o momento de eversão máxima do tornozelo diminui com a idade no andar, favorecendo a estabilidade. Essa diferença pode ser explicada pela imaturidade 
no rolamento do pé, associada ao desenvolvimento incompleto do arco plantar ou pela imaturidade dos músculos flexores da planta do pé $(3,37,39,79)$.

Menores valores de pico de pressão nos dedos foram encontrados para o G5 em relação ao G4 e podem ser explicados pela diminuição da velocidade e aumento dos valores de DPP no retropé, como explicitado anteriormente.

\subsection{Avaliação entre o Pé Direito e o Pé Esquerdo}

Houve pouca diferença entre os valores médios para as variáveis de DPP para o pés direito e esquerdo. Estudos que avaliaram o caminhar em crianças normais em velocidade livre não encontraram diferenças entre os dados de pressão plantar dos pés direito e esquerdo $(6,20)$. Houve diferença apenas para as variáveis força máxima relativa na região do antepé $(\mathrm{p}=0,011)$ e tempo de contato no hálux $(\mathrm{p}=0,044)$ do grupo G4 e para a variável área de contato na região do retropé $(p=0,047)$ do grupo $G 5$.

Nos estudos utilizados como referência de Bosch et al. $(3,6,73)$ também não foi encontrada diferença entre o pé direito e esquerdo durante o andar em crianças, por este motivo os autores calcularam a média entre os dois pés. A simetria entre os membros parece se manter também durante a corrida em adultos em diferentes velocidades sobre as esteira (53) e em diferentes superfícies (29).

Alguns estudos, como o de Fourchet et al. (61) com corredores adolescentes, Ho et al. (55) durante o correr de adultos na esteira, ou de Ford et al. (80) ao testar o correr com atletas em diferentes superfícies, avaliam a DPP em apenas um membro. Estes estudos foram realizados com a palmilha de avaliação de pressão plantar, que é posicionada em um dos pés. Os resultados do presente estudo sugerem que o mesmo pode ser realizado com crianças de 4 a 6 
anos idade e na plataforma, não havendo a necessidade de avaliar ambos os membros.

\subsection{Velocidade do Correr}

A velocidade diminuiu significativamente para todos os grupos durante $o$ período de um ano (-19\% para o G4, -26\% para G5 e -33\% para G6). Isso se deve provavelmente a motivação durante a execução do correr sobre a plataforma. É possível que durante a primeira avaliação os avaliados estivessem mais motivados para a realização das tentativas, visto que na segunda avaliação os avaliados já estavam familiarizados com os procedimentos e avaliadores. Além disso, por apresentarem um padrão do correr muito variável, alguns sujeitos precisaram repetir várias vezes as tentativas para que fossem coletas 5 tentativas válidas não intencionais para cada pé.

Estudos $(75,81)$ realizados durante o caminhar, encontraram que valores absolutos para a velocidade tendem a aumentar com a idade, mas esse aumento não é identificado quando se normaliza os dados de velocidade pelo comprimento de membros inferiores e pela aceleração da gravidade. Sugerindo que as diferenças observadas tenham origem na diferença de tamanho entre os sujeitos.

Dados para velocidade durante o correr de crianças não foram encontrados, mas segundo Bramble e Lieberman (14) entre $2,3 \mathrm{~m} / \mathrm{s}$ e $2,5 \mathrm{~m} / \mathrm{s}$ ocorre a transição voluntária da caminhada para o correr em humanos. Contudo Ho et al. (55) testou o correr na esteira de mulheres jovens nas velocidades 1,5, 2,0 e 2,5 m/s, considerando 1,5 m/s a velocidade lenta de corrida. Em um estudo com atletas adolescentes, foram utilizadas velocidades de cerca de $3 \mathrm{~m} / \mathrm{s}$ para o trote e $5 \mathrm{~m} / \mathrm{s}$ para o correr (61). Os dados apresentados oferecem novos dados sobre o comportamento da velocidade e da distribuição de pressão plantar durante o correr em crianças. 
A velocidade influencia a avaliação do correr, pois interfere nos ângulos articulares, nas forças de reação do solo, nos momentos articulares, nas forças de impacto e na distribuição de pressão plantar (13). A velocidade também influencia a área de contato, a força máxima, o pico de pressão e o tempo de contato de corredores adultos e adolescentes $(13,55,61,76)$. Dessa forma, os dados para as variáveis de DPP devem ser analisados com cautela.

A motivação foi relatada como um fator importante durante a avaliação e pesquisa em crianças, seja para capacidades físicas ou habilidades motoras, e pode influenciar a forma com a criança realiza a marcha, alterando o padrão de movimento e a velocidade com a qual a criança corre (2). Considerando que algumas crianças realizaram mais de 50 tentativas para a aquisição de 5 tentativas válidas para ambos os pés e mesmo parece ocorrer em pesquisas realizadas durante o andar em crianças (39) e que não há diferença entre os dados médios de DPP entre o pé direito e o pé esquerdo, tanto no correr como no caminhar em crianças e adolescentes $(6,20,61)$, sugere-se que em futuras pesquisas avaliando distribuição de pressão plantar durante a marcha em crianças seja avaliado apenas um dos pés. Essa escolha diminuiria consideravelmente o número de tentativas realizadas por cada sujeito, bem como o tempo de cada coleta dos dados para cada indivíduo e para a pesquisa de uma forma geral. 


\section{CONCLUSÕES}

Enquanto a área de contato durante o correr aumentou no período de um ano em várias regiões do pé e no pé total para os três grupos, a região do mediopé não apresentou diferenças no período de um ano. Houve um tendência a diminuição dos valores médios de pico de pressão e de força máxima relativa na região do retropé e aumento no pé total e antepé, com exceção do grupo com 5 anos que teve a menor velocidade da avaliação 2.

As principais diferenças na distribuição de pressão plantar entre os grupos ocorreram entre o grupo de 6 anos e os demais grupos. Com uma tendência de valores de pico de pressão, força máxima, área de contato e tempo de contato maiores para o grupo de 6 anos no pé total, antepé, hálux e dedos em relação aos demais grupos tanto nas duas avaliações.

Não há diferença entre os resultados obtidos nas tentativas realizadas com o pé direito e o pé esquerdo. Considerando o grande número de tentativas realizadas para a aquisição completa dos dados, estudos futuros podem considerar avaliar o correr apenas em um dos pés.

O crescimento e desenvolvimento do pé parece não estar completo aos 6 anos de idade, com valores crescentes de comprimento do pé e mudanças na sua estrutura.

Os dados do estudo podem ser utilizados como referência para comparação com estudos que analisem a locomoção humana envolvendo o correr em crianças ou adultos. 


\section{REFERÊNCIAS BIBLIOGRÁFICAS}

1. Martin PE, Sanderson DJ. Biomechanics of walking and running. Exercise and sport science. Philadelphia: Lippincot Williams \& Wilkins; 2000. p. 639-59.

2. Gallahue DL, Ozmun JC. Compreendendo o Desenvolvimento Motor. Bebês, crianças, adolescentes e adultos. $1^{\mathrm{a}}$ ed. São Paulo,2001.

3. Bosch K, Gerß J, Rosenbaum D. Preliminary normative values for foot loading parameter of the developing child. Gait and Posture. 2007;26:238-47.

4. Tong JWK, Kong PW. Reliability of footprint geometric and plantar loading measurements in children using the Emed M System. Gait and Posture. 2013;38(2):281-6.

5. Filippin NT, Barbosa VLP, Sacco ICN, Costa PHLd. Efeito da obesidade na distribuição da pressão plantar em crianças. Rev Bras de Fisio. 2007;11(6):495-501.

6. Bosch K, Gerß J, Rosenbaum D. Development of healthy children's feet Nine-year results of a longitudinal investigation of plantar loading patterns. Gait and Posture. 2010;32:564-71.

7. Faloppa F, Albertoni WM. Guia de Ortopedia e Traumatologia. $1^{\text {a }}$ Edição ed: Manole; 2008.

8. Cappozzo A. Gait analysis methodology. Human Movement ans Science. 1984;3:27-50.

9. Norkin C, Levangie K. Joint structure and function. A comprehensive analysis. $2^{\text {a }}$ Edição ed. EUA: Library of Congress; 1992.

10. Medved V. Measurement of Human Locomotion. London: CRC Press; 2001. 
11. Corraza S, Mundermann L, Chaudhari M, Dermattio T, Cobelli C, Andracchi P. Motion Capture System to Study Musculoskeletal Biomechanics: Visual Hull Computer Vision and Image Understanding. Anals of Bimedical Engineering. 2006;34(6):1019-29.

12. Capecci M, Bombace VG, Cardinali V, Cecchetelli V, Saltarelli F, Coccia $\mathrm{M}$, et al. Gait analysis of stroke subjects walking at different self-selected speed. Gait and Posture. 2006;24:43-4.

13. Novacheck TF. The biomechanics of running. Gait and Posture. 1998;7:77-95.

14. Bramble DM, Lieberman DE. Endurance running and the evolution of Homo. Nature. 2004;432(7015):345-52.

15. Carvalho D. Manual do corredor:Bomecânica 2014 [cited 201420 de dezembro]. Available from: http://www.ortopediadoesporte.com.br/manual-docorredor-biomecanica/.

16. Seeley MK, Umberger BR, Shapiro R. A test of the functional asymmetry hypothesis in walking. Gait and Posture. 2008;28:24-8.

17. Gurney B. Review, Leg length discrepancy. Gait and Posture. 2002;15:195-206.

18. White SC, Gilchrist LA, Wilk BE. Asymmetric Limb Loading with True or Simulated Leg-Length Differences. Clin Orthop Pel Res. 2004;1(421):28792.

19. Song KM, Halliday SE, Little DG. The effect of limb length discrepancy on gait J Bone Joint Surg. 1997;79A(11):1690-8.

20. Lythgo N, WIlson C, Galea M. Basic gait and symmetry measures for primary school-aged children and young adults whilst walking barefoot and with shoes. Gait and Posture. 2011;30(4):502-6. 
21. Mercer JA, Bates BT, Dufek JS, Hreljac A. Characteristics of shock attenuation during fatigued running. Journal of Sports Sciences. 2003;21(11):911-9.

22. Nigg BM. Biomechanics of Running Shoes. Champaign: Human Kinetics; 1986.

23. Gerritsen KG, Bogert AJvd, Nigg BM. Direct dynamics simulation of the impact phase in heel-toe running. Journal of Biomechanics. 1995;28(6):661-8. 24. Leo ATD, Dierks TA, Ferber R, Davis IS. Lower extremity joint coupling during running: a current update. Clinic in Biomechanics. 2004;19(10):983-91.

25. Hreljac A. Impact and Overuse Injuries in Runners. Medicine \& Science in Sports \& Exercise. 2004;36(5):845-9.

26. Feehery RV. The biomechanics of running on different surfaces. Clinics in Podiatric Medicine and Surgery. 1986;3(4):649-59.

27. Ferris DP, Liang K, Farley CT. Runners adjust leg stiffness for their first step on a new running surface. J Biomech. 1999;32(8):787-94.

28. Williams KR. A Dinâmica da Corrida. In: Zatsiorsky V, editor. Biomecânica do Esporte. Rio de Janeiro: Guanabara Koogan; 2004. p. 125-42.

29. Tessuti V, Tormbini-Souza F, Ribeiro AP, Nunes AL, Sacco IdC. In-shoe plantar pressure distribution during running on natural grass and asphalt in recreational runners. J Sci Med Sport. 2010;13(1):151-5.

30. Gerlach KE, White HW, Burton JM, Dorn JM, Leddy JJ, Horvath PJ. Kinetic changes with fatigue and relationship to injury in female runners. Medicine \& Science in Sports \& Exercise. 2005;37(4):657-63.

31. Kyrolainen H, Avela J, Komi PV. Changes in muscle activity with increasing running speed. J Sports Sci. 2005;23(10):1101-9. 
32. Eils E, Streyl M, Linnenbecker S, Thorwesten L, Volker K, Rosenbaum D. Characteristic plantar pressure distribution patterns during soccer-specific movements. Am J Sports Med. 2004;32(1):140-5.

33. Weist R, Eils E, Rosenbaum D. The influence of muscle fatigue on electromyogram and plantar pressure patterns as an explanation for the incidence of metatarsal stress fractures. Am J Sports Med. 2004;32(8):1893-8.

34. Cavanagh PR, Williams KR. The effect of stride length variation on oxygen uptake during distance running. Med Sci Sports Exer. 1982;14:30-5.

35. Saibene F, Minetti AE. Biomechanical and physiological aspects of legged locomotion in humans. Eur J Appl Physiol. 2003;88:297-316.

36. Arendse R, Noakes TD, Azevedo L, Romanov N, Schwellnus M, Fletcher G. Reduced eccentric loading of the knee with the pose running method. Medicine and Science in Sports and Exercise. 2004;36:272-7.

37. Alvarez C, DeVera M, Chhina H, Black A. Normative data for tha dynamic pedobarometric profiles of children. Gait and Posture. 2008;28(2):30915.

38. McCrory JL, Young MJ, Boulton AJM, Cavanagh PR. Arch Index as a Predictor or Arch Heigh. The Foot. 1997;7:79-81.

39. Bertsch C, Unger H, Winkelmann W, Rosenbaum D. Evaluation of early walking patterns from plantar pressure distribution measurements. First year results of 42 children. Gait and Posture. 2004;19:235-42.

40. Chan CW, Rudine A. Foot biomechanics during walking and running. Mayo Ciln Proc. 1994;69(5):448-61.

41. Abboud RJ. Relevant foot biomechanics. Current Orthopaedics. 2002;16(3):165-79. 
42. Putti A, Arnold G, Cochrane L, Abboud R. Normal pressure values and repeatability of the EMED® ST4 system. Gait and Posture. 2008;27(3):501-5. 43. Sneyers CJL, Lysens R, Feys H, Andries R. Influence of malalignment of feet on the plantar pressure pattern in running. Foot Ankle Int. 1995;16:624-32.

44. Roy KJ. Force, pressure and motion measurements in the foot: current concepts. Ciln Podiatr Med Surg. 1988;5:491-508.

45. Rogers MM, Cavanagh PR. Glossary of biomechanical termas, concepts, and units. Phys Ther. 1984;64:1886-902.

46. Orlin MN, McPoil TG. Plantar pressure assessment. Phys Ther. 2000;80:399-409.

47. Alexander IJ, Chao EYS, Johnson KA. The assessment of dynamic footto-ground contact forces and plantar pressure distribution: a review of the evolution of current techniques and clinical applications. Foot Ankle. 1990;11:152-67.

48. Han TR, Paik NJ. Quantification of the path of center of pressure using an f-scan in shoe transducer. Gait and Posture. 1999;10:248-54.

49. Cavanagh PR, Hewitt FG, Perry JE. In-shoe plantar pressure measurement: a review. The Foot. 1992;2:185-94.

50. McPoil TG, Cornwall MW, Yamada W. A comparison of two in-shoe plantar pressure measurement systems. Lower Extremity. 1995;2:95-103.

51. Schaff PS. An overview of foot pressure measurement systems. Clin Podiatr Med Surg. 1993;10:403-15.

52. Taunton J, Ryan M, Clement D, McKenzie D, Lloyd-Smith D, Zumbo B. A retrospective case-control analysis of 2002 running injuries. British Journal of Sports Medicine. 2002;36(2):95-101. 
53. Chuckpaiwong B, Nunley JA, Mall NA, Queen RM. The effect of foot type on in-shoe plantar pressure during walking and running. Gait \& Posture. 2008;28:405-11.

54. Rodgers MM. Dynamic biomechanics of the normal foot and ankle during walking and running. Phys Ther. 1988;68(12):1822-30.

55. Ho I-J, Hou Y-Y, Yang C-H, Wu W-L, Chen S-K, Guo L-Y. Comparison of plantar pressure distribution between different speed and incline during treadmill jogging. Journal of Sports Science and Medicine. 2010;9:154-60.

56. Tessutti V, Trombini-Souza F, Ribeiro AP, Nunes AL, Sacco IdCN. Inshoe plantar pressure distribution during running on natural grass and asphalt in recreational runners. Journal of Science and Medicine in Sport. 2008;13:151-5.

57. Fourchet F, Kuitunen S, Girard O, Millet G-P. Comparison of foot plantar distribution between training and spike shoes in young sprinters. Science \& Sports. 2007;24:176-8.

58. Nagel A, Fernholz F, Kibele C, Rosenbaum D. Long distance running increases plantar pressures beneath the metatarsal heads A barefoot walking investigation of 200 marathon runners. Gait \& Posture. 2007;27:152-5.

59. Fourchet F, Horobeanu C, Loepelt H. Foot, Ankle, and Lower Leg Injuries in Young Male Track and Field Athletes. international journal of Athletic Therapy \& training. 2011;19:19-23.

60. Niemeyer P, Weinberg A, Schmitt H, Kreuz P, Ewerbeck V, Kasten P. Stress fractures in adolescent competitive athletes with open physis. Knee Surgerz, Sports Traumatology, Arthroscopy. 2006;14:771-7.

61. Fourchet F, Kelly L, Horobeanu C, Loepelt H, Taiar R, Millet GP. Comparison of plantar pressure distribution in adolescent runners at low vs. high running velocity. Gait \& Posture. 2012;35:685-7. 
62. Lieberman D, Venkadesan M, Werbel W, Daoud A, D'Andrea S, Davis I, et al. Foot strike patterns and collision forces in habitually barefoot versus shod runners. Nature. 2010;463:531-5.

63. Hasegawa H, Yamauchi T, Kraemer W. Foot strike patterns of runners at the $15-\mathrm{km}$ point during an elite-level half marathon. J Strength Cond Res 2007;21:888-93.

64. Larson P, Higgins E, Kaminski J, Decker T, Preble J, Lyons D. Foot strike patterns of recreational and sub-elite runners in a long-distance road race. Journal of Sports Sciences. 2011;29(15):1665-73.

65. Bertelsen M, Jensen J, Nielsen M, Nielsen R, Rasmussen S. Footstrike patterns aamong novice runners wearing a conventional, neutral running shoe. Gait \& Posture. 2012.

66. Cavanagh PR, LaFortune MA. Ground reaction forces in distance running. Journal of Biomechanics. 1980;13:397-406.

67. Ardigo L, Lafortuna C, Minetti A, Mongnoni P, Saibene F. Metabolic and mechanical aspects of foot landing type, forefoot and rearfoot strike, in human running. Acta Physiologica Scandinavica. 1995;155:17-22.

68. Stackhouse C, Davis I, Hamill J. Orthotic intervention in forefoot and rearfoot strike running patterns. Clinical Biomechanics. 2004;19:64-70.

69. Williams D, McClay I, Manal K. Lower extremity mechanics in runners with a converted forefoot strike pattern. Journal of Applied Biomechanics. 2000;16:210-8.

70. Kleindienst F, Campe S, Graf E, Michel K, Witte K. Differences between fore- and rearfoot strike running patterns based on kinetics and kinematics. XXV ISBS Symposium; Ouro Preto, Brazil : ; 2007. p. 252-5. 
71. Willems T, Witvrouw E, Cock AD, Clercq DD. Gait-related risk factors for exercise-related lower-leg pain during shod running. Medicine \& Science in Sports \& Exercise. 2007;39(2):330-9.

72. Malina R, Bouchard C, Bar-Or O. Crescimento, Maturação e Atividade Física. $1^{a}$ Edição ed. São Paulo: Editora Phorte 2009.

73. Bosch K, Nagel A, Weigend L, Rosenbaum D. From "first" to "last" steps in life - pressure patterns of three generations. Clin Biomech. 2009;24:676-81. 74. VanderLinden ML, Kerr AM, Hazlewood ME, Hillman SJ, Robb JE. Kinematic and kinetic gait characteristics of normal children walking at a range of clinicaly relevant speeds. J Pediatr Orthop. 2002;22(6):800-6.

75. Mariano CRE, David AC. Varáveis espaço-temporais do andar em velocidade lenta, livre e rápida em crianças de 3 a 8 anos. Rev de Educ Física. 2010;21(4):625-32.

76. Kernozek TW, Zimmer KA. Reliability and running speed effects of inshoe loading measurements during slow treadmill running. Foot Ankle Int. 2000;21:749-52.

77. The emed ${ }^{\circledR}$-systems 2014 [cited 201404 de novembro]. Available from: http://www.novel.de/novelcontent/emed.

78. Cavanagh PR, Rodgers MM. The arch index: a useful measure from footprints. J Biomech. 1987;20(5):547-51.

79. Samson W, Dohin B, Desroches G, Chaverot J-L, Dumas R, Cheze L. Foot mechanics during the first six years of independent walking. Journal of Biomechanics. 2011;44(7):1321-7.

80. Ford KR, Manson NA, Evans BJ, Myer GD, Gwin RC, Jr. RSH, et al. Comparison of in-shoe foot loading patterns on natural grass and synthetic turf. Journal of Scienc and Med in Sport. 2006;9:433-40. 
81. Hillman SJ, Stansfield BW, Richardson AM, Robb JE. Development of temporal and distance parameters of gait in normal children. Gait and Posture. 2009;29:81-5. 
ANEXO I - Parecer de Aprovação do Comitê de Ética

FACULDADE DE CIËNCIAS DA
SAUUDE DA UNIVERSIDADE DE
BnB
BRASILIA - CEPIFS-UNB

\section{PARECER CONSUBSTANCIADO DO CEP}

\section{DADOS DO PROJETO DE PESOUISA}

Titulo da Pesquisa: Distribuigáo de Presslo Plantar durante a corrida em criangas

Pesquisador: Taina Newes Vieira

Ároa Temática:

Versšo: 4

CAAE: 19809513.5 .0000 .0030

Instituição Proponente: Faculdade de Educaģso Flasca - UnB

Patrocinador Principal: Financiamento Proprio

\section{DADOS DO PARECER}

Nümero do Parocer: 788.162

Data da Relatoria: 10/09/2014

\section{Apresentaçăo do Projeto:}

Trata-se de projeto de mestrado.A locomoçlo humana vem sendo amplamente estudada ao longo dos anos. Tanto a marcha como a corrida sfio objetpe de vírias pesquisas dentificas que buscam compreender esses movimentos táo fundamentais ao ser humano. Duas pessoas nf́o se boomoverem de forma ibentica, contudo, alguns padiobes podem ser identilicados. A descriçấo desses padr6es, contidas em diversas obras cientificas, auxiliam e orientam berapeutas, ortopedletas, pediatras, engenheiros biomédicos, especialistas em reabilitaçlo, clentistas do esporte e

treinadores esportivos em suas praticas. O comer, por sua vez, impce maiores cargas mecanicas a sistema musculoesquelético do que o andar,gerando maiores demandas do sistema locomotor e deixando-o mais suscetivel à lesces. InformaçCes acerca de oomo escas carges afetam as forgas que devem ser sustertadas pelo pe sf́o importantes na avaliaç̧o do desenwolvimento motor e para o desernvolvimento de peodutos, como os tenis esportivos infantis. Dados de referencia ou normativas sobre a corrida em crianças de diterentes faixas etárias tem papel fundamental na avaliagáo de distungoes e no desenvolvimento de crianças. No entanto, nSto foram encontrados estudos sobee a distribuiçso da pressso plantar durante o correr em crianças em diterentes taixas etarias. 


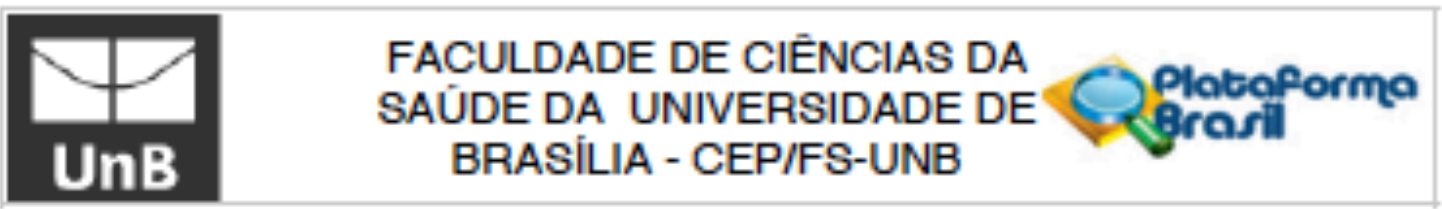

Conthumglle do Pwecer the sis

\section{Objetivo da Pesquisa:}

Descrewer o comportamento da distribulçlo da peessío plantar dumante o correr em crianças dos 3 acs 10 anos de idade.

\section{Avalią̧ấo dos Riscos o Benetícios:}

Um questionário será aplicado e somente as crianças saudítveis participaram da pesçulea. Estas correrb̆ descalcas sobre um tapete de EVA em uma regito leplada da escola por 9 metros, com intervalo de descanso entre as tentativas e sempre que for necessário. Nî́ seráo utilizados métodos invasivos. A criança podera se negar a oontinuar a sua participaçáo na pesqutsa a qualquer momento. Sendo assim, náo existem riscos relacionados a pesquisa.

Beneticios: Caso alguma anomalia seja detectada na corrida durante a análise dos dados, os pais da criança serfo informados, para que procurem avaliaçlo especializada.

\section{Comentírios e Consideraçóces sobre a Pesquisa:}

A perquisa 6 relevante e foi ajustada conforme recomendapóses do CEP

Consideraçōes sobre os Termos de apresentạ̧ão obrigatória:

Os pesquisadores ajustamam o TCLE e anexaram o bermo de aszentimento.

\section{Conclusōes ou Pendéneias e Lista de Inadequap̧óes:}

O TCLE fol adequado conforme solicitado e termo de assentimento fol apresentado e está adequado.

NSo hal pendencias.

Protocolo de pesqulsa em conformidade com a Pesolugsto CNS 466/2012 e complementares.

Situşão do Parocer:

Apeovado

Nocessita Aprocią̧ấo da CONEP:

NSo

\section{Consideraçōes Finais a critério do CEP:}

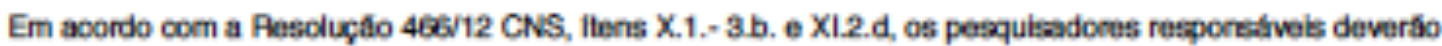
apresentar relatórios parcial semestral e final do projeto de pesquisa, contados a partir da data de aprovagito do protocolo de pesquisa.

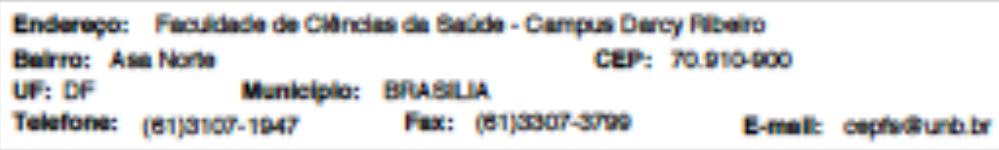


ANEXO II - Relatório produzido pelo sistema Emed.

\section{novel.de}

\section{science}

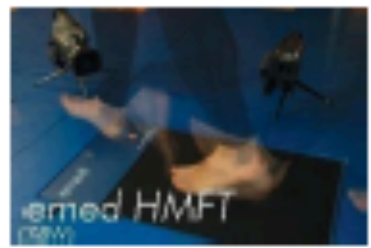

Patlent

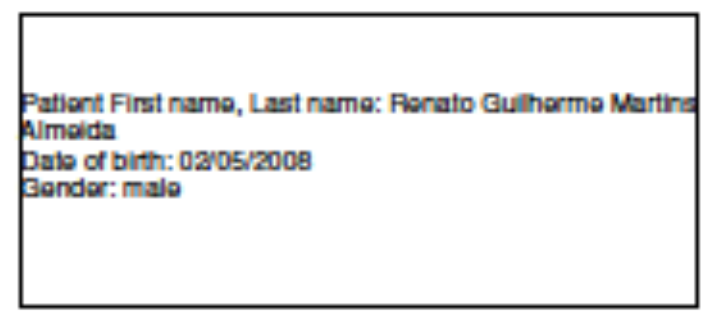

\section{History}

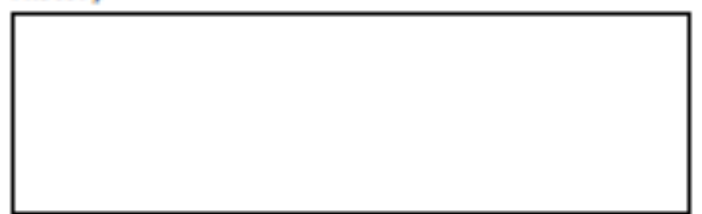

Comments

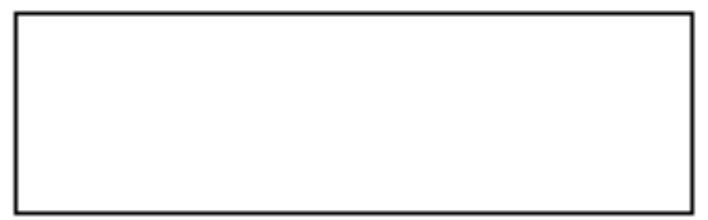

Diagnosis, results

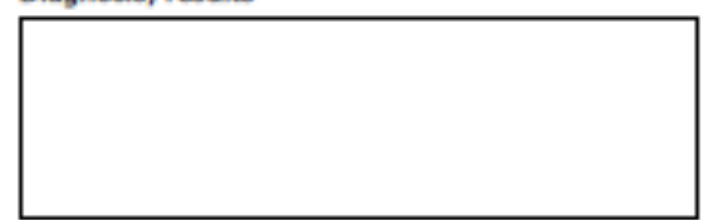

Conclusion, therapy
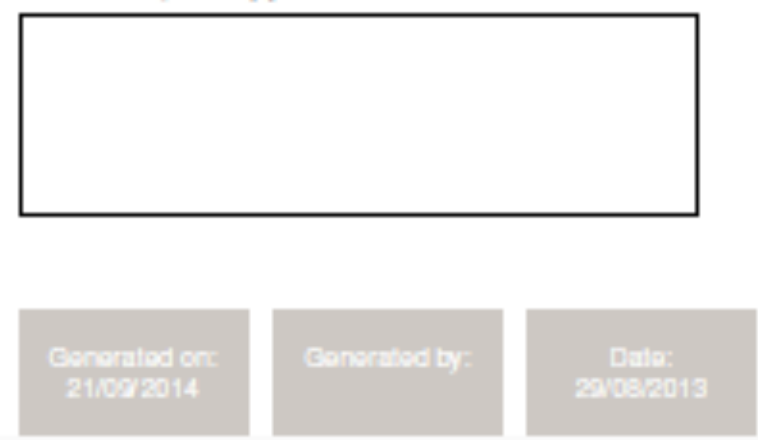
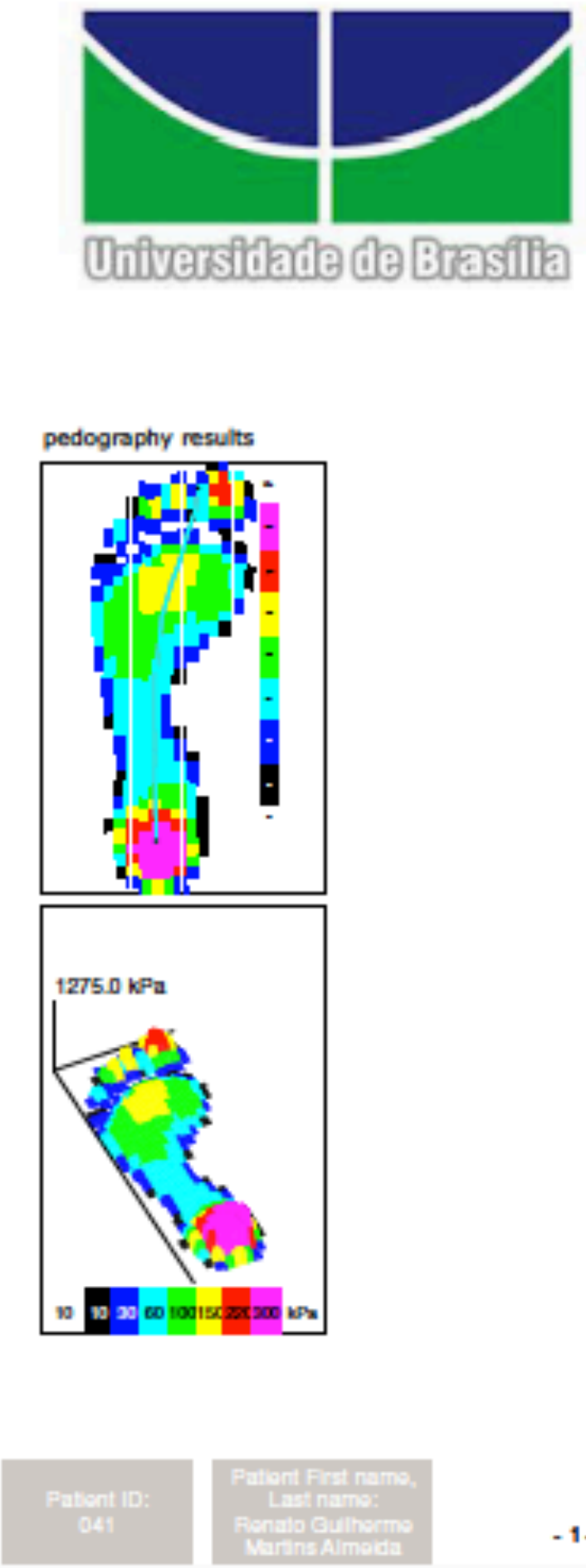

$-1-$ 


\section{novel.de}

\section{science}

Total number of files: 1

\begin{tabular}{|l|l|}
\hline File (Left foot) & Comments \\
\hline Gullhomn_Martina_Almolda_Ranalo_6.dat & \\
\hline
\end{tabular}

averaged maximum pressure picture

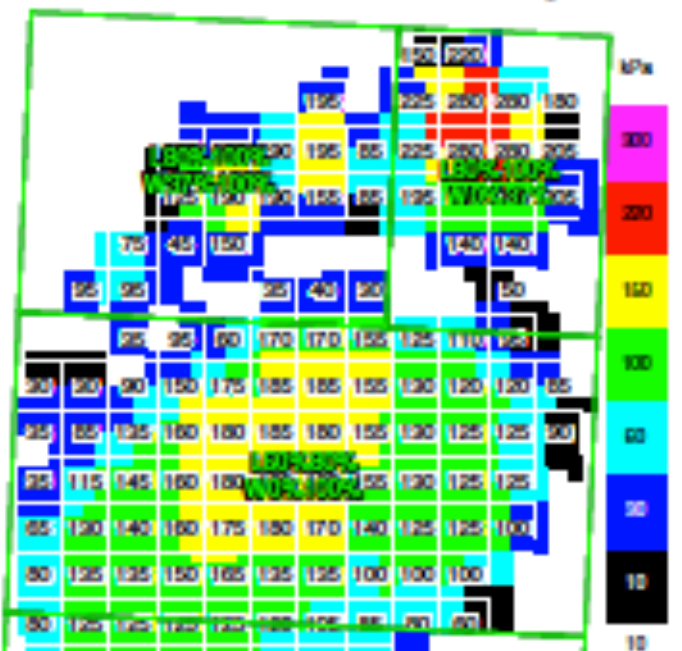

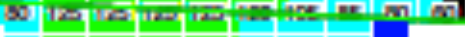

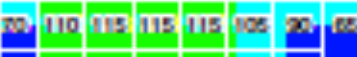

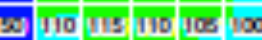

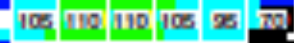

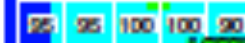

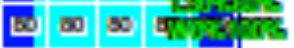

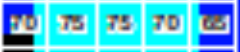

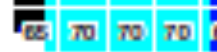

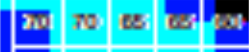

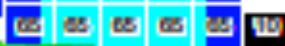

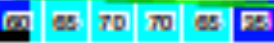

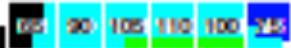

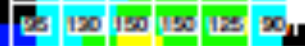

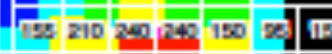

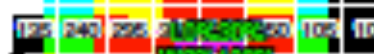

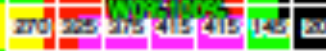

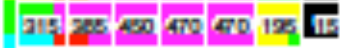

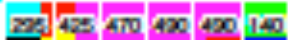

his seces 4454

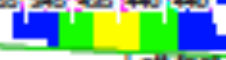

Lett fort 


\section{novel.de $\vec{y}$}
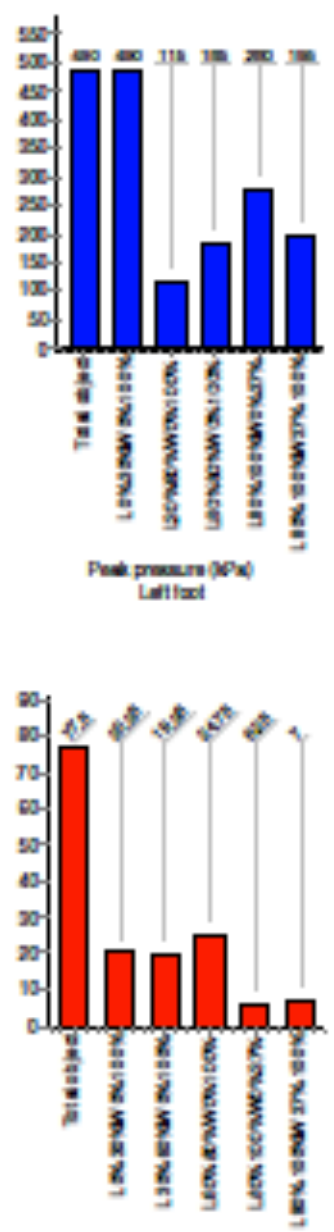

corbey

\section{science}
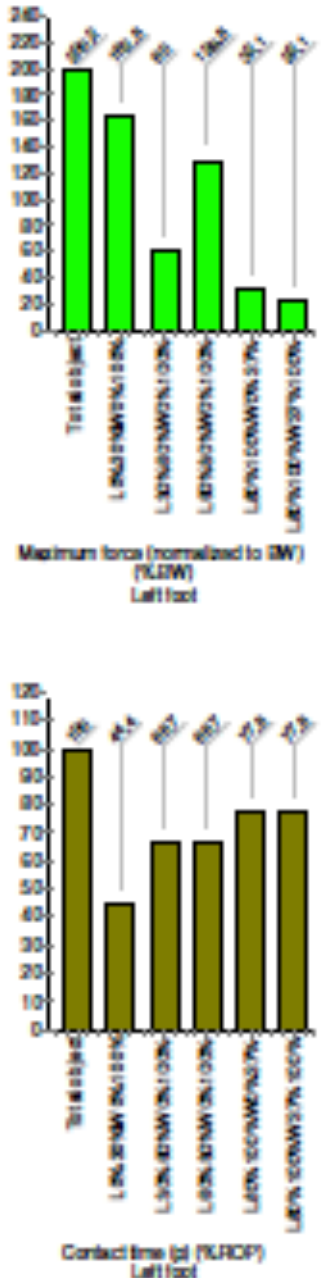

Litixi 


\section{novel.de?}

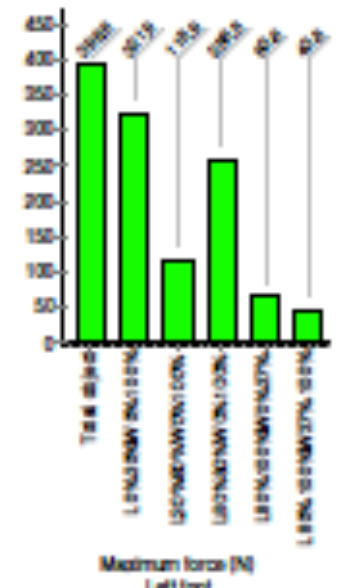

Letifxt

Parameters ) masks (statistics)

\begin{tabular}{|c|c|c|c|c|c|c|}
\hline Parameters & $\begin{array}{l}\text { Total } \\
\text { abject }\end{array}$ & $10 \% 30$ & 13096 & L60\% & $180 \%$ & $280 \%$ \\
\hline \multicolumn{7}{|c|}{ Left foot } \\
\hline Maximum force (N) & 396,6 & 321,9 & 118,2 & 256,5 & 63,6 & 43,8 \\
\hline Maximum force (normalized to $B W)$ (KEW) & 200,2 & 162,5 & 60,0 & 129,5 & 32,1 & 22,1 \\
\hline Peak preasure (kPa) & 490,0 & 490,0 & 115,0 & 185,0 & 280,0 & 195,0 \\
\hline Contact tame (p) (XROP) & 100,0 & 44,4 & 66,7 & 66,7 & $\pi, 8$ & 77,8 \\
\hline Contact area (cmin) & 77,50 & 20,25 & 19,25 & 24,75 & 6,25 & 7,00 \\
\hline
\end{tabular}




\section{averaged maximum pressure picture}

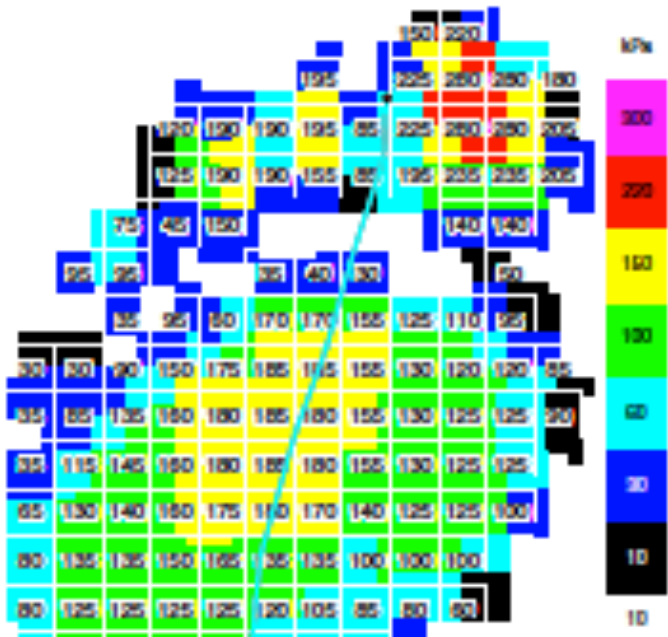

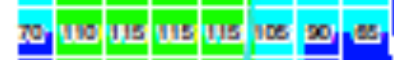

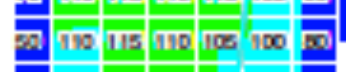

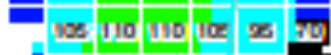

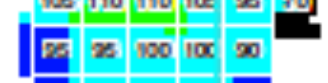

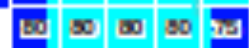

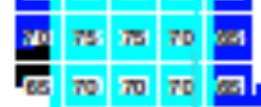

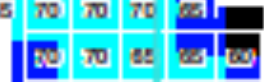

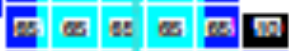

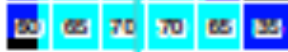

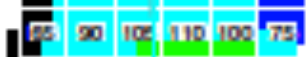

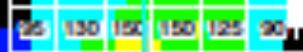

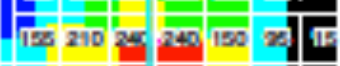

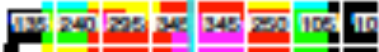

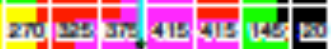

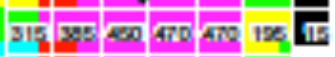

240240000000

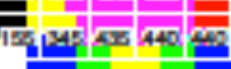

Left foot 
APÊNDICE I - Carta convite a participação na pesquisa

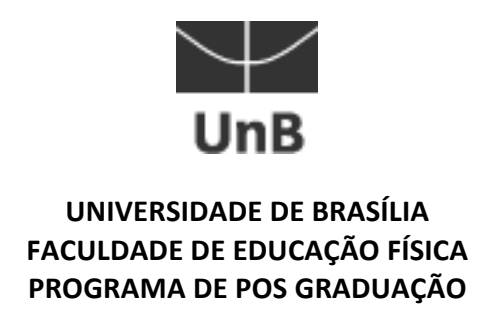

Bom dia!

Estamos realizando uma pesquisa que vai analisar a corrida em crianças. Esse estudo será utilizado para o desenvolvimento de calçados adequados para as crianças, para o desenvolvimento de aulas de atividade física mais adequadas para cada idade e para melhor compreender como se desenvolve a corrida a medida que a criança cresce.

Caso o senhor(a) autorize, o seu(ua) filho(a) correrá aproximadamente 7 metros cinco vezes com descanso entre as tentativas (num total de 35 metros). Também mediremos o peso e altura. No total, avaliaremos o seu(ua) filho(a) por apenas 5 minutos. Apesar de curta a participação da população é indispensável e sem ela não conseguimos produzir conhecimento. A identidade e imagem dos participantes não será divulgada, sendo sua participação voluntária e anônima.

Caso concorde com a participação do menor pelo qual você é responsável, por gentileza:

1. Responda o questionário;

2. Assine o Termo de Consentimento Livre Esclarecido (fique com uma cópia);

3. Envie para a Escola/Professora os dois documentos.

Agradecemos muito a sua colaboração!

Tainá Neves

Pesquisadora responsável

(61) $9277-0010$ 
APÊNDICE II - Termo de Conscentimento Livre e Esclarecido

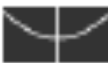 \\ UnB \\ UNIVESSIDADE De Bustua \\ FACULDROE DE EOUCACÁ F́lGaca \\ moceterma oe nos eraduacho \\ CAMPUS UNIVERSTIARIO DARCY RIEELO \\ Bnasitu - of \\ TELEFONE (061) $3109-2512$ \\ mww fef.unb.br
}

\title{
Termo de Consentimento Livre e Esclarecido - TCLE
}

$O($ (a) seu/sus) filho(a) está sendo convidado(a) a participar do projeto que avalia distribuiçäo de pressäo plantar durante a corrida em crisnças. $O$ objetivo desta pesquiss é analisar e comparar as variáveis que caracterizam a Distribuiçăo de Pressão Plantar entre diferentes idsdes.

$O(\Delta)$ senhor $(a)$ receberó todos os esclarecimentos necessários antes e no decorrer da pesquisa e the asseguramos que o nome do seu filho näo sparecerá sendo mantido o mais rigoroso sigilo stravés da omissão total de quaisquer informsções que permitam identifić. $10[\mathrm{a}]$.

A participaçăo do(a) seu(sua) fíno(s) será stravés de um questionário, ums avaliaçăo antropométrica e uma svaliaçäo das cargas plantares na corrida, realizados na escola do seu filho e no horório de sula, na data combinsda com um tempo estimado de 10 minutos para sus realizaçăo. Para isso, seu fillho deverá ficar descalço, contundo o pesquissdor será responsável por garantir que o ambiente esteja limpo e näo ofereça risco a saúde.

Näo há benefícios relscionados a participaçăo na pesquisa, além de que caso seu fítho apresente alguma variaçăo em relaçäo a corrida normal o senhor será informado para que possa procurar os profissionais adequados. Não haveró nenhum tipo de pagamento ou gratificaçăo financeira pela sua participaçōo. Também não há custos em relação a participaç̧̄o na pesquisa. $O[(\mathrm{a})$ senhor( $(\mathrm{a})$ tem direito a pleitear indenizaçäo em caso de danos decorrentes da participsçấo na pesquisa, além de ressarcimento de despesss provenientes da participaçäo.

Informsmos que o[a] Senhor(a) e o(s) seu(sua) filiho(s) pode se recussr a responder (ou participar de qualquer procedimento) qualquer questĩo que the traga constrangimento, podendo desistir de partioipar da pesquisa em qualquer momento sem nenhum prejuizo para o(a) senhor(a). Sua participaçăo é voluntária, isto é, näo há pagamento por sua colaboração.

Os resultados da pesquisa serão úteis na avalisçâo da corrida saudável em crianças e na deteç̧ão de possiveis problemas relacionados a desenvolvimento normal do movimento com o crescimento e desenvolvimento infantil. Os dados seröo divulgados na Universidade de Brasília podendo ser publicados posteriormente. Os dados e materisis utilizados na pesquisa fícarão sob a gusrda do pesquisador por um período de no mínimo cinco anos, após isso serăo destruidos ou mantidos na instituiçăo.

Este projeto foi Aprovsdo pelo Comitê de Ética em Pesquiss da Faculdade de ciências da Soúde da Universidsde de Brasilis. Se o(a) Senhor(s) tiver quslquer dúvids em relaç̧o à pesquisa, por favor telefone para Tainá Neves Vieira, na Universidade de Brasilia, telefone (61) 9277-0010, no horário comercial ou pelo e-mail taina_nvêohotmail.com.

Este documento foi elsborsdo em duss viss, uma ficaró com o pesquisador responsável e a outra com o responsável pelo sujeito da pesquisa e assinante do documento.

Tainá Neves Vieira 
CONSENTIMENTO DA PARTICIPAÇẼo dA CRIANÇA COMO SUJEITO DA PESQUISA

Eu,

RG

CPF

, abaixo assinado, autorizo

a participar do estudo DISTRIBUIÇR̃ DE PRESSĨo PLANTAR DURANTE A CORRIDA EM CRIANÇAS sob responsabilidade da pesquisadora Tainá Neves Vieira como sujeito voluntário. Fui devidamente informado e esclarecido pelo pesquisador sobre a pesquisa, os procedimentos nela envolvidos, assim como os possiveis riscos e benefícios decorrentes do participaçäo. Foi me garantido que posso retirar meu consentimento a qualquer momento, sem que isso leve à qualquer penalidade.

Brasilia, de de 20

Assinatura do Responstóvel pela criança

Assinatura do Pesquisador Responsável Tainá Neves Vieira 
APÊNDICE III - Questionário entregue os responsáveis

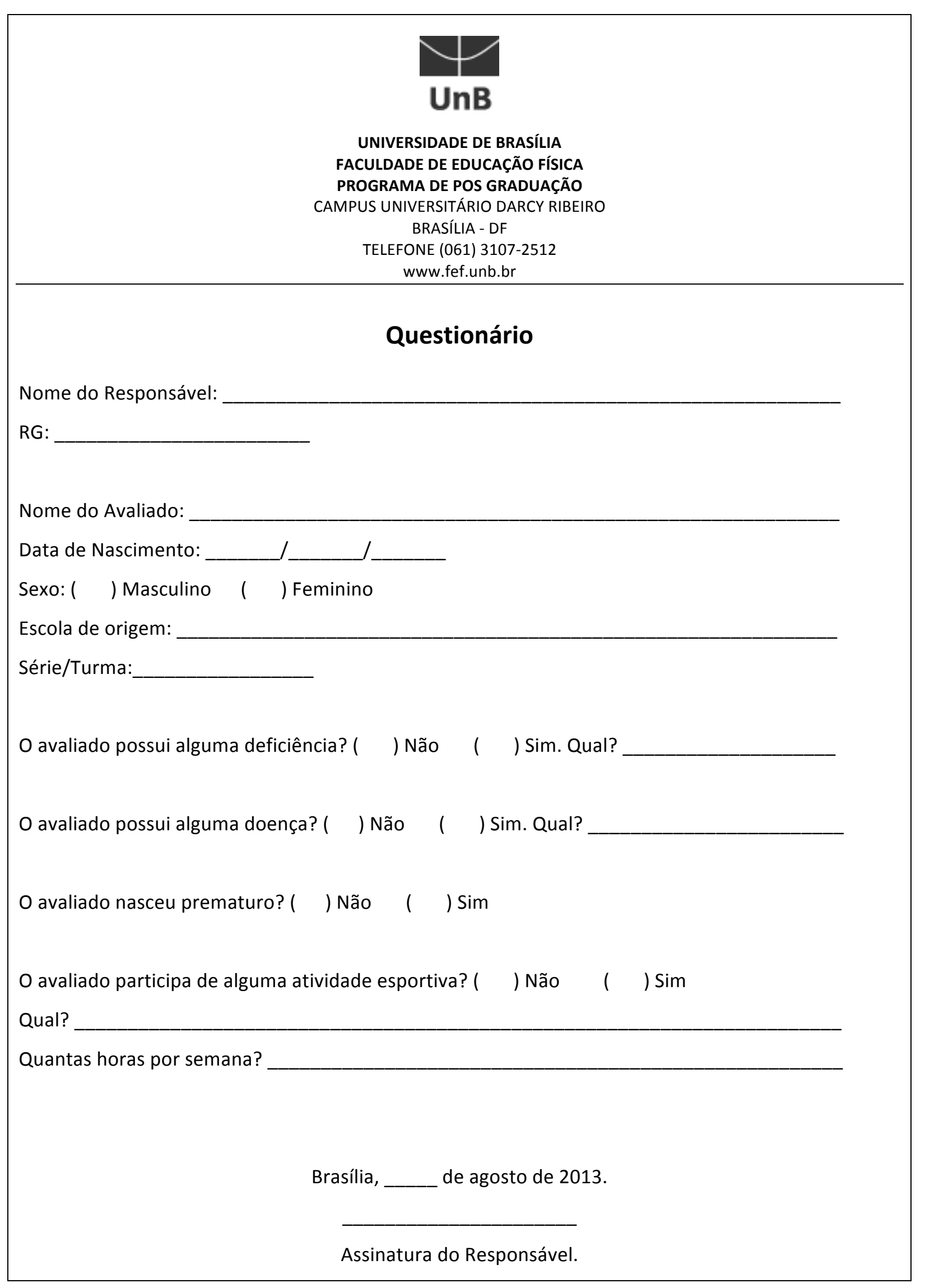

